CuPAUAM. 18-1991, 227-259

\title{
FORTIFICACIONES URBANAS DE EPOCA BAJOIMPERIAL EN HISPANIA. UNA APROXIMACION CRITICA (*) (PRIMERA PARTE)
}

\author{
CARMEN FERnANDEZ OCHOA \\ ANGEL MORILLO CERDAN \\ DEPTO. PREH. Y ARQUEOLOGK \\ UNIEERSIDAD AUTONOMU DE MADRID
}

Resumen

El propósito de este artículo es presentar un catálogo actualizado, sistemático y crítico sobre el estado de la investigación de las fortificaciones tardorromanas de las ciudades hispanas que sirva como base para fururos estudios relacionados con esta importante parcela de la arqueologia de la Hispania Romana.

\section{Summary}

The purpose of this article is to present an up-to-date, systematic and critical catalogue on the state of research about late roman fortifications of Hispanic cities, which can be used as a base for future studies related to this important area of "Hispania Romana" archeology.

(*) El presente trabajo forma parte de un grupo de tres estudios sobre el estado de la cuestión de las fortificaciones romanas en Hispania. Se ha publicado un primer artículo (A. Morillo, "Fortificaciones campamentales de época romana en España" en A.Esp.A. 64, 1991, 135-190) y próximamente se completará la serie con la publicación del estudio de las fortificaciones altoimperiales. Una de las autoras (C. Fernández Ochoa) realizó parte de estos trabajos durante una estancia de investigación en Roma concedida por la D.G.I.C. y T. del Ministerio de Educación y Ciencia (Programa de P. y M.P.I., años 1988 y 1991).

\section{INTRODUCCION}

El paisaje urbano de las ciudades tardorromanas se define, en gran medida, por las murallas. El análisis de las fortificaciones ciudadanas del Bajo Imperio se encuentra a medio camino entre lo civil y lo militar, entre su carácter de refugio y su validez como punto de resistencia, entre la necesidad de su erección como elemento de prestigio y su valor defensivo ante peligros reales o posibles. 
La determinación de todos estos elementos es una difícil tarea que requiere la conjunción de innumerables datos históticos y arqueológicos no siempre fáciles de conseguir. El silencio de las fuentes escritas para muchas áreas del Imperio y la deficiencia en la obtención de registros arqueológicos fiables, convierten el estudio de los recintos urbanos en una de las parcelas de la investigación más sometida al juego de las hipótesis razonables pero de difícil demostración.

La comprensión del tema pasa necesariamente por una primera consideración global de carácter histórico. El problema de las fortificaciones tardorromanas se encuadra dentro de un largo proceso de transformaciones que se inicia a fines del siglo II d.C. y evoluciona a lo largo del siglo III d.C. o "siglo de la crisis". Los cambios operados en el seno del Imperio entre Septimio Severo y Diocleciano marcan, en términos de organización política, socio-económica y militar, el principio y desarrollo de un cambio estructural irreversible en la sociedad romana tradicional del Alto Imperio.

Dentro de estos cambios, y a los efectos que ahora nos interesan, los historiadores señalan variaciones del modelo de organización urbana -centrado en la ciudad- que sería reemplazado por el de organización rural, extraterritorial e independiente de la ciudad (Bravo, 1989, 225). Se trató de un proceso largo y complejo en el que las ciudades vieron limitado su propio desarrollo sin que ello implicara su total decadencia ni menos aún su ruina generalizada como pretendia la historiografia anterior a los años setenta. Para el caso hispano, y a pesar de la escasa información disponible todavía, Arce ha reivindicado, creemos que con razón, la vitalidad de bastantes núcleos urbanos de Hispania a lo largo de los siglos finales del Imperio (Arce, 1982, 99-100).

Otro aspecto importante en la consideración de nuestro tema son las transformaciones operadas en el ámbito de la estrategia milizar entre el Alto y el Bajo Imperio. Los estudios clásicos de Luttwak (Luttwak, 1976) o el más reciente de Ferril (Ferril, 1986), junto con las aportaciones de Mac Nicoll (Mac Nicoll, 1982) y de Rebuffat (Rebuffat, 1986) así como los famosos congresos "Roman Frontier Studies" (desde 1949) ilustran de forma clara muchas de estas cuestiones.

La legislación romana que acompañó los cambios estratégicos no es muy abundante pero sí puede resultar ilustrativa. Como es sabido, el sistema defensivo romano sufrió una dura prueba en tiempos de Marco Aurelio y Commodo. Aunque las fronteras fueron rápidamente restauradas, se inició en esos momentos la tendencia a construir murallas en centros civiles. Para controlar estas iniciativas, Marco Aurelio ordenó que toda ciudad que deseara tener muralla, debía consultarlo con el Emperador (Digesto, L, 10, 6). En la misma línea, con Septimio Severo se legisla Neque muri neque portae babitari sine permissu principis propter fortuita incendia possunt (Digesto, XLIII, 6, 2).

Según la Historia Augusta, Galieno, en su zona de soberanía, mandó reparar y fortificar algunas murallas de ciudades, pero no hay constancia legislativa de tal actuación. El afán constructivo de Diocleciano se refleja del mismo modo en los autores tardios (Lander, 1984, 164 y 184).

Durante el siglo IV d.C. la preocupación por el cuidado de las murallas y el estímulo para su construcción mediante la participación ciudadana se recoge claramente en el capítulo 15 del Codex Theodosianus (Arce, 1982, 73-74).

Vemos, por tanto que la propia legislación romana nos indica un cambio de mentalidad que tendría una de sus manifestaciones más singulares en el paso de una cierta desconfianza hacia las defensas ciudadanas a la incitación a su construcción. Incluso se deja a las gentes vivir cerca del recinto con tal de que lo testauren (Digesto, $\mathrm{XV}, 1,51$ ).

En el terreno estrictamente arqueológico, contamos con numerosos trabajos referidos a las fortificaciones del Bajo Imperio, bien se trate de fuertes militares o de murallas urbanas. Los estudios más importantes hasta principios de los años 80 se recogen en dos obras de síntesis, la de Lander (Lander, 1984), que trata de fortificaciones militares, y la de S. Johnson (Johnson, 1983), que 
intenta dar una visión global incluyendo tanto los fuertes militares y los fortines rurales, como los recintos ciudadanos.

La ingente cantidad de publicaciones de la última década forma un auténtico corpus informativo que excede con mucho las intenciones de este trabajo. Anotatemos tan solo algunos títulos referidos a la problemática de los recintos urbanos de la pars occidentalis del Imperio. En 1980 se celebró un interesante coloquio Roman Urban Defences in the West (1983), que junto con la obra editada por King y Hening, The Roman West in the Third Century (1981), permiten vislumbrar, desde aportaciones de signo muy diverso, el conjunto general de la problemática.

Para una visión general de la Galia remitimos a la apretada síntesis de Bedon, Chevalier y Pinon (Bedon, Chevalier y Pinon, 1988, 77-118), aunque conviene advertir que las investigaciones francesas y belgas continúan siendo muy prolíficas en los aspectos urbanísticos teferidos precisamente a las murallas.

Algo similar se puede decir para el caso británico. La fuerte tradición de estudios sobre fronteras, motivados por la especificidad de los muros de Adriano y Antonino, y las numerosas excavaciones realizadas, han generado un corpus doctrinal extraordinario, especialmente para los asentamientos altoimperiales, uno de cuyos ejemplos más recientes podría ser la obra editada por Webster (Webster, 1988). Para el período que nos ocupa, además de los trabajos sobre el Saxon Shore puede verse el estudio crítico de Crickmore (Crickmore, 1984).

La monografía de S. Johnson (Johnson, 1983), antes citada, no contempla el caso del Norte de Africa, en concreto, las cuestiones relativas a la Tingitana como parte integrante de la Diocesis Hispaniarum a partir de Diocleciano. Conocemos algunas obras monográficas o estudios tipológicos para el limes de esta zona (Euzenat, 1989 y Welsby, 1990) junto con las interesantes aportaciones sobre defensas urbanas de autotes como Rebuffat (Rebuffat, 1974), E. Lenoir (Lenoir, 1986) - Hallier (Hallier, 1986), por citar tan solo algunos ejemplos.

En este breve repaso bibliográfico cabe anotar por último que en fechas recientes se han empezado a publicar una serie de trabajos sobre la Muralla Aureliana de Roma (Cozza, 1986 y 1987).

Por lo que respecta al caso hispano, el ptimer autor que trató el tema de forma global fue Richmond en 1931 y sus ideas marcaron, en parte, la lfnea de investigación seguida por algunos autores espafioles (Richmond, 1931). En 1949 Taracena aumentó el número de recintos atribuibles al periodo tardorromano y compiló los datos más significativos (Taracena, 1949).

En 1960 inicia Balil una serie de trabajos sobre la defensa de Hispania en el Bajo Imperio son artículos especificos sobre las fortificaciones hispanas de este momento histórico (Balil, 1960; 1963; 1965). Balil matizó algunas cuestiones del trabajo de Taracena y amplió el catálogo inicial. Estos trabajos supusieron, además, el primer intento de telacionar las murallas de Hispania con las del resto del Imperio tomando como base aspectos tipológicos e históricos. En 1961 publicó una de las monograffas más valiosas como estudio de conjunto, referida a las murallas de Barcelona (Balil, 1961). Con motivo del Bimilenario de León, de nuevo dedicó su atención al tema de la defensa de Hispania (Balil, 1970).

En 1972, uno de sus discípulos, Arias Vilas, realizó una monografía sobre las murallas de Lugo que incluye un apéndice sobre las fortificaciones hispánicas del Bajo Imperio y la crisis del siglo III d. C. reclamando la necesidad de revisar a fondo los conjuntos arqueológicos (Arias Vilas, 1972).

Hasta estas fechas, tanto las visiones de conjunto como los estudios parciales -se citarán en el catálogo- habían establecido una relación causa-efecto entre murallas y defensa del territorio. En 1982, Arce, siguiendo a algunos investigadores franceses, planteó por primeta vez que la causa de la erección de murallas ciudadanas había que buscarla tanto en los motivos de prestigio de la pro- 
pia ciudad como en las razones de prevención y defensa, al menos hasta el siglo V d.C. (Arce, 1982, 73-80). En su obra encontramos una visión global sobte las murallas tardías con una fuerte crítica hacia las deficientes excavaciones y publicaciones habidas hasta el momento.

Las seis páginas que S. Johnson dedica a Espafia en su obra de síntesis son interesantes, aunque resultan demasiado escuetas. Acusa a los investigadores hispanos de un excesivo subjetivismo a la hora de datar los recintos, y dedica atención preferente a las llamadas fortalezas "legionarias" del Noroeste, justificando su existencia como puntos de control del paso de los minerales hacia el sur de la Galia (Johnson, 1983, 134-141).

Por último, cabe resefiar una breve comunicación de Blázquez al congreso del limes celebrado en Carnuntum, donde se reiteran las visiones de siempre sin aportar datos interpretativos nuevos (Blázquez, 1986).

\section{CATALOGO DE FORTIFICACIONES URBANAS BAJOIMPERIALES PROVINCIA TARRACONENSIS}

A continuación presentamos el catálogo de las fortificaciones bajoimperiales hispanas, en el que incluimos no sólo aquellas cuya datación está perfectamente constatada, sino también las que en algún momento -con mayor o menor fundamento- han sido consideradas como tales.

\section{Barcino (Barcelona)}

El recinto amutallado tardorromano de la colonia Barcino se encuentra entre los mejor conservados de la Península. Grandes lienzos del mismo aún resultan visibles en la trama urbana de la ciudad, a pesar de las significativas destrucciones llevadas a cabo durante el pasado siglo, que afectaron especialmente a las puertas. Los tramos conservados se concentran en el sector septentrional de la muralla, cortespondiendo a la plaza Nueva, la plaza de la Catedral, la calle de Tapinería, la plaza de Ramón Berenguer III el Grande y la calle del Subteniente Navarro. La mitad meridional del perimetro amurallado prácticamente ha desaparecido.

El primer levantamiento topográfico de la muralla fue realizado en 1834 por los arquirectos Mestres Oriol y Mestres Gramatxes, cuyos planos han llegado hasta nuestros días y constituyeron la la base de otros publicados posteriormente, entre los que destacan el de Pi Arimón, de 1854 . Sin embargo, hasta 1931 no se realiza un estudio cientifico del recinto amurallado, trabajo que debemos a Richmond y que apenas tuvo eco dentro de nuestras fronteras (Richmond, 1931). En 1943, Durán y Sanpere publica los resultados de las primeras excavaciones llevadas a cabo en el área de la muralla, conctetamente en la Plaza del Rey (Durán i Sanpere, 1943), en las que pudo observarse por primera vez la cara interna de la muralla, seguidas dos años más tarde por las excavaciones en la Bajada de la Canonja, con idénticas conclusiones (Durán i Sanpere, 1945). En 1958 aparece una breve descripción del recinto amurallado (Florensa, 1958). Precedido en el tiempo por algunos trabajos menores (Balil, 1956; Balil, 1957), el completo estudio monográfico publicado en 1961 por Balil (Balil, 1961) supuso un hito fundamental dentro del estudio de las murallas romanas de Barcelona y de las murallas tardorromanas hispánicas en general. En éste se abordan por primera vez cuestiones constructivas y estratégicas que posteriormente tendran una amplia repercusión en nuestro país. Desde esta fecha el conocimiento arqueológico de las fortificaciones barcelonesas ha progresado de forma significativa gracias a investigadores como Serrà-Rafols (Serrá- 


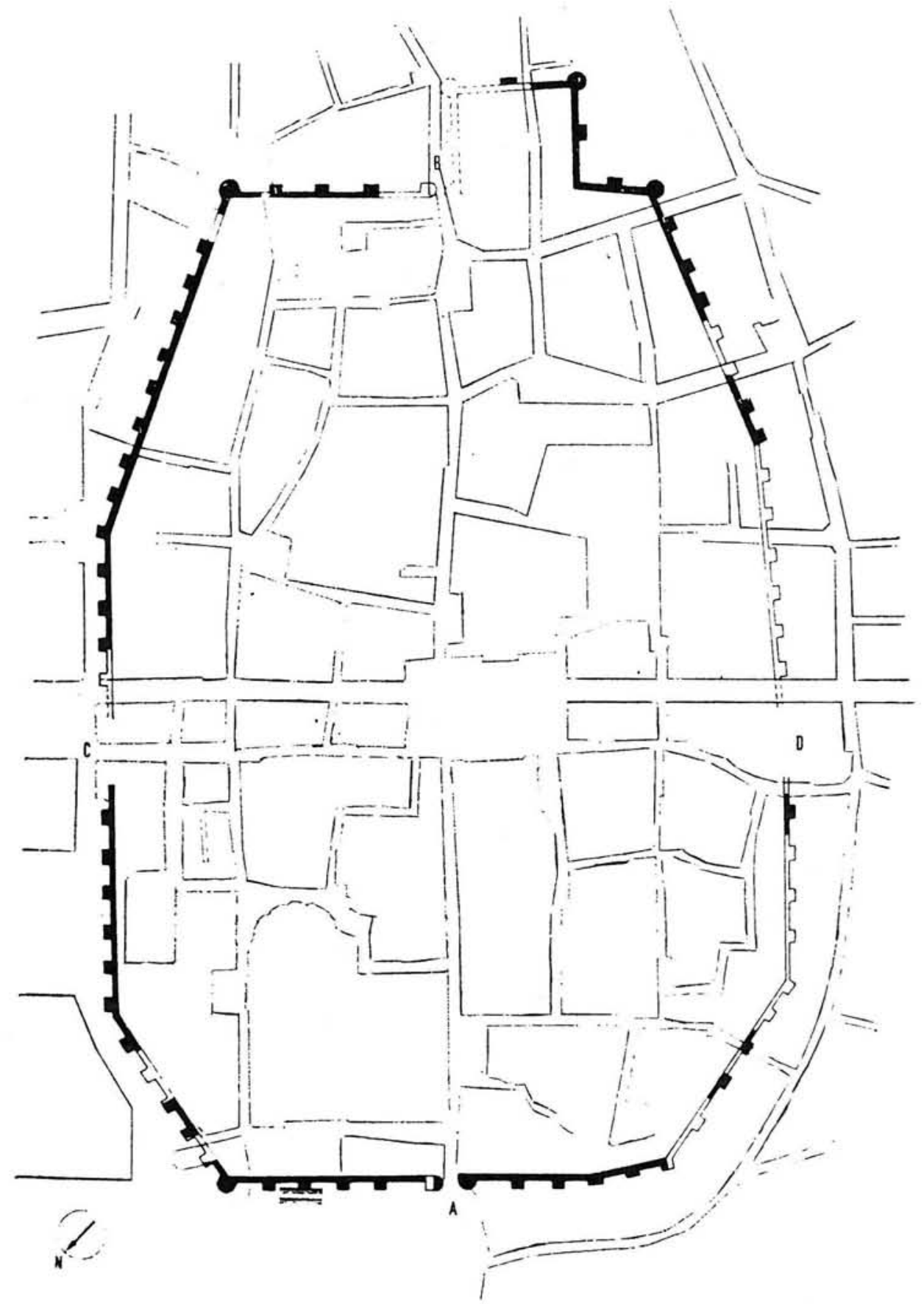

Planta general de las murallas de la Colonia Barcino. A, Porta Decumane; B, Porta Praetoria; C, Porta Principalis Dextra; D, Porta Principalis Sinistra. (J. Oriol Granados, 1977-8) 
Rafols, 1959; 1964; 1967), Pallares (Pallares, 1969; 1970), Duran i Sanpere (Duran i Sanpere, 1969), Verrie (Verrie y VV.AA., 1973), Bassegoda Nonell (Bassogoda Nonell, 1975) y Sol Valles (Sol Valles, 1977), que excavan en distintos puntos del recinto. Los trabajos de Granados, centrados preferentemente en la puerta de la plaza Nueva, antigua puerta decumana de la colonia, han aclarado cuestiones de excepcional interés sobre la cronologla y evolución histórica de la fortificación (Granados, 1976 b; 1977-8; Granados y V.V.A.A., s/f). En 1984 Granados publica un excelente estado de la cuestión sobre la fortificación altoimperial, que completa la aún vigente descripción de Balil con los datos descubiertos con posterioridad (Granados, 1984), definiendo uno de los conjuntos amurallados de época tardortomana mejor conocidos de toda la Península.

La colonia romana de Barcino, asentada sobre un altozano situado entre las desembocaduras de los ríos Llobregat y Besós y denominado "Taber" en la Edad Media, adopta una planta rectangular con ángulos achaflanados, con una orientación noroeste-sureste, y ejes máximos de $825 \mathrm{X}$ 550 metros, que definen una superficie de 9 has. (Balil, 1961, 61). La ciudad se adapta a la forma de la muralla, que presenta un perímetro de 1270 metros, flanqueado por torres cuadrangulares de 6,30 metros de anchura y de 5,30 a 6 metros de frente, separadas por lienzos de 6 a 10 metros de longitud. Las torres constan de dos cuerpos de 9 metros de altura cada uno, el superior con dos pisos. A la altura del piso inferior de las torres, que corresponde a la parte superiot de las cortinas, corre el camino de tonda, desde el que se accede a las torres a través de arcos de medio punto. En el segundo piso de las torres se abren ventanas, también de medio punto (Balil, 1961, 71-3).

Las torres de los ángulos del recinto son circulares o achaflanadas (Balil, 1961, 50), planta que ha podido confirmarse en el torreón de la plaza de los Arrieros (Verrie y VVAA., 1973). Sin embargo, la torre correspondiente al ángulo noroccidental de la fortificación, ocupada tradicionalmente por la Casa de la Pía Almoyna, adopta una planta octogonal (Balil, 1961, 75), lo que hasta el momento constituye un unicum dentro del panorama de las murallas bajoimperiales hispanas. Las excavaciones realizadas en la misma en 1968 revelaron que se comenzó a edificar con planta semicircular, al igual que el resto de las torres angulares, para después, por alguna razón desconocida, variar su alzado (Durán i Sanpere, 1969, 65).

El recinto amurallado presenta en su lado sudoriental un extraño cuerpo rectangular de difícil explicación (Pallares, 1969, 18), que para Granados se trata de un añadido bajoimperial que no existía en el recinto original augusteo (Granados, 1976 a, 291).

De las cuatro puertas que se abrían en la muralla, correspondientes al final de los dos ejes principales -cardo y decumano máximos-, tan sólo una ha llegado hasta nosotros en un estado regular de conservación, la llamada Puerta decumana o del noroeste. Sin embargo, las tres restantes conservaron buena parte de su fisonomía original hasta mediados del siglo pasado, momento en que, de acuerdo con las nuevos principios urbanísticos, fueron derribadas. A partir de los grabados y fotografias conservados, Balil las clasificó como de tres tipos: con torres de flanqueo semicitculares -puertas decumana y praetoria-, con torres de flanqueo cuadradas -puerta principalis dextra o del Call- y con torres de planta poligonal -puerta principalis sinistra o de la Cárcel- (Balil, 1956, 279). Recientemente Granados ha corregido la interpretación de Balil sobre la Puerta de la Cárcel, proponiendo una planta cuadrada para las torres laterales, que configurarian un acceso similar al de la puerta suroeste o del Call (Granados, 1977-8, 268-9).

La puerta mejor conocida arqueológicamente es la noroeste o de la Plaza Nueva, correspondiente a la antigua puerta decumana y definida por dos torres semicitculares, cuya planta se adapta a las condiciones topográficas impuestas por la existencia de un acueducto altoimperial, que se integra en la obra tardía. Tan sólo se conserva el arranque de las jambas del arco o arcos centrales, 
mientras la parte superior, hoy desaparecida, ha sido magistralmente reconstituida por Balil a partir de los grabados del pasado siglo (Balil, 1961, 78). Recientes excavaciones realizadas en la torre de flanqueo derecha han revelado que la muralla bajoimperial incorpora la puerta de tres vanos del primer recinto amurallado, dotándola de las modificaciones necesarias para un recinto tardio, tales como la prolongación de su corredor y el añadido de las dos torres laterales (Granados, 1976 b; $1977-8 ; 1984,288$ ). Las interpretaciones de la puerta praetoria o de Regomir apuntan hacia una solución parecida, con un arco doble entre torres semicirculares (Pallares, 1969, 27-9; Granados y VV.AA, s/f).

A partir de la publicación de las excavaciones realizadas en la Plaza del Rey (Durán i Sanpere, 1943) quedó suficientemente constatado que el recinto amurallado romano estaba constituido en realidad por dos murallas paralelas adosadas, realizadas mediante técnicas constructivas muy diferentes. La cara interna de la muralla está edificada en sillarejo de reducidas dimensiones sin escuadrar, dispuesto en hiladas más o menos regulares de piedra arenisca del Montjuich. Idéntica estructura adopta el paramento externo de este primer recinto amurallado, visible en el interior de la muralla tardía y separado del paramento interno por un relleno de mortero de cal y pequeñas piedras. La anchura total de esta primera fortificación es de unos 2 metros y se eleva sobre unos cimientos de profundidad variable -entre 0,50 y 1,27 metros- y una banqueta de cimentación de 10 a $20 \mathrm{cms}$. de anchura, visible sólo por la cara interna. En las puertas y en los ángulos los sillares con almohadillado rústico sustituyen al sillarejo (Granados, 1976 a, 219-20; Granados, 1984, 284-6). Duran i Sanpere (Duran i Sanpere, 1943, 58) y Balil (Balil, 1961, 62-3). A pesar de las afirmaciones de este último investigador (Balil, 1961, 63), la muralla altoimperial carecía de torres (Granados, 1976 a, 220), y debia alcanzar al menos ocho metros de altura (Granados, 1984, 286).

En época tardia, a este primer recinto se le adosa por su cara externa una segunda fortificación cuyo paramento externo, que constituye en la actualidad el frente de la muralla barcelonesa, está realizado en opus quadratum con grandes sillares calizos bien escuadrados y trabajados con almohadillado rústico, que en ocasiones adoptan una colocación "a soga y tizón". Entre ellos se encuentran numerosos sillares y piezas arquitectónicas reutilizadas. El espacio entre el muro externo del primer recinto y el paramento externo de la muralla se rellena con un mortero de piedras y restos arquitectónicos y constructivos trabados con argamasa rojo-amarillenta. Los cimientos de este segundo recinto bajoimperial son poco profundos -entre 0,60 y 1 metro-, están realizados con argamasa y piedras de distinto tamaño, y sobre ellos se dispone una banqueta de uno o dos sillares, salientes entre 10 y 20 cms. La estructura completa de la muralla alcanza un espesor de 3,54 metros y una altura de 9, 19 metros, excluyendo los merlones, que protegerían el camino de ronda (Balil, 1961, 66-8). A excepción del cuerpo rectangular del lado sureste, los dos recintos coinciden exactamente en todos los puntos de la muralla explorados (Granados, 1984, 280-4). La hipótesis de Pallarés (Pallares, 1969, 18-20), que consideraba que el primer recinto era rigurosamente rectangular y en época tardía los ángulos se achaflanaban, se ha revelado como erróneo.

A pesar de las observaciones de Balil, no conocemos en profundidad la estructura de las partes superiores de la muralla tardía, muy modificadas posteriormente, así como la auténtica finalidad de una estructura interpretada como una escalera de acceso al camino de ronda situada en la Casa Padellás (Balil, 1961, 80-1)

Uno de los principales problemas que ha planreado tradicionalmente el recinto amuraliado de Barcelona ha sido el de su cronologia, aspecto indisolublemente ligado a la existencia de dos recintos adosados. Siguiendo los criterios de índole histótica que han primado en la interpretación. arqueológica hasta hace pocas décadas, los primeros investigadores que se ocuparon de las mura- 
Ilas de la capital catalana consideraron que se trataba de un recinto de nueva planta erigido con motivo de la penetración de bandas de franco-alemanes en el Imperio durante el reinado de Galieno -hacia el 260-1 d. J.C-, y que, según las fuentes, habian asolado la costa catalana (Richmond, 1931, 98-9; Taracena, 1949, 433 y 437-8). Balil consideró que los dos recintos adosados se edificaron en un momento muy próximo en el tiempo, pero respondfan a características constructivas muy diferentes. El primer perímetro amurallado se encontratía dentro del llamado estilo "legionario", término acuñado por Richmond; en un momento algo posterior, aprovechando los lienzos del primer recinto, se edifica una segunda muralla, inspirada en la primera fase de la muralla aureliana de Roma. La observación de la técnica edilicia de la muralla le lleva a situar cronológicamente la erección del segundo recinto en época tetrárquica, entre el 270 y el 310 d. J. C. (Balil, 1957, 22830). Ya Richmond había propuesto una fecha parecida a partir de las inscripciones epigráficas reutilizadas en la muralla (Richmond, 1931, 98). El hallazgo de un mosaico en la Bajada de Santa Eulalia, fechado en la primera mitad del siglo III d. C. y cortado por la muralla bajoimperial, le sirve a Balil para afirmarse en sus opiniones iniciales (Balil, 1961, 84; 1962, 49).

Fca. Pallares, superado el problema arqueológico que suponía para la arqueologia barcelonesa los hallazgos romanos del Montjuich (para esta cuestión Granados, 1984, 270-5, entre otros crabajos) es la primera investigadora que califica abiettamente el primer recinto amurallado como augusteo (Pallares, 1969, 42), seguida algunos años más tarde por otros autores (Bassegoda Nonell, 1975, 101; Granados, 1976 a, 222; 1976 b; 1984, 277). Todos ellos sin embargo, emplean argumentos históricos y de técnica edilicia, ya que hasta el momento no ha aparecido ninguna estratigrafia incontestable (Granados, 1984, 286-7). Lo mismo podemos decir del recinto bajoimperial, con una cronología post quem basada en el mosaico de la Bajada de Santa Eulalia y de una moneda de Claudio II el Gótico -años 268-70 d. C.- hallada en la torre circular de la plaza de los Arrieros (Verrie y VV.AA., 1973, 772-3). Este constituye hoy en día uno de los principales problemas de interpretación de la muralla tardía de Barcelona, problemática que comparte con la inmensa mayoría de los recintos bajoimperiales peninsulares. Recientemente Jarrega ha replanteado la cronología de esta fortificación, señalando la escasa consistencia de los datos empleados para su datación y planteando una cronología de principios del $\mathrm{V}$ a partir del hallazgo de monedas del siglo IV en el relleno interior de la torre número 11 de la calle de la Tapinerfa (Jarrega, 1991, 330-1). Sin embargo, sus argumentos, a pesar de la notable novedad que implican, son del mismo tipo que los empleados por sus predecesores, esto es, fechas post quem y, por lo tanto, relativos.

Nos queda, por último, apuntar otra cuestión oscura de las fortificaciones barcelonesas: desconocemos si las descripciones que dio Balil sobre la estructura de las partes altas de las torres y lienzos corresponden en realidad a la muralla tardorromana o si ésta habrá sufrido importantes modificaciones en época medieval que pudieran haber enmascarado su estructura original. En cualquier caso, aún contando con futuras exploraciones más minuciosas, resultará muy dificil responder a esta cuestión.

\section{Gerunda (Gerona)}

La ciudad romana de Gerunda, punto estratégico dentro de las comunicaciones transpirenaicas, estuvo rodeada durante el Bajo Imperio por un potente recinto fortificado que se encuentra entre los mejor constatados arqueológicamente de toda la Península. Grandes lienzos del mismo han llegado hasta nuestros días en los sectores de Las Aguilas, Plaza de Santo Domingo-calle de la Escuela Pía, Casa Pastors y Portal de Sobreportes, integrados dentro de la muralla medieval -cono- 


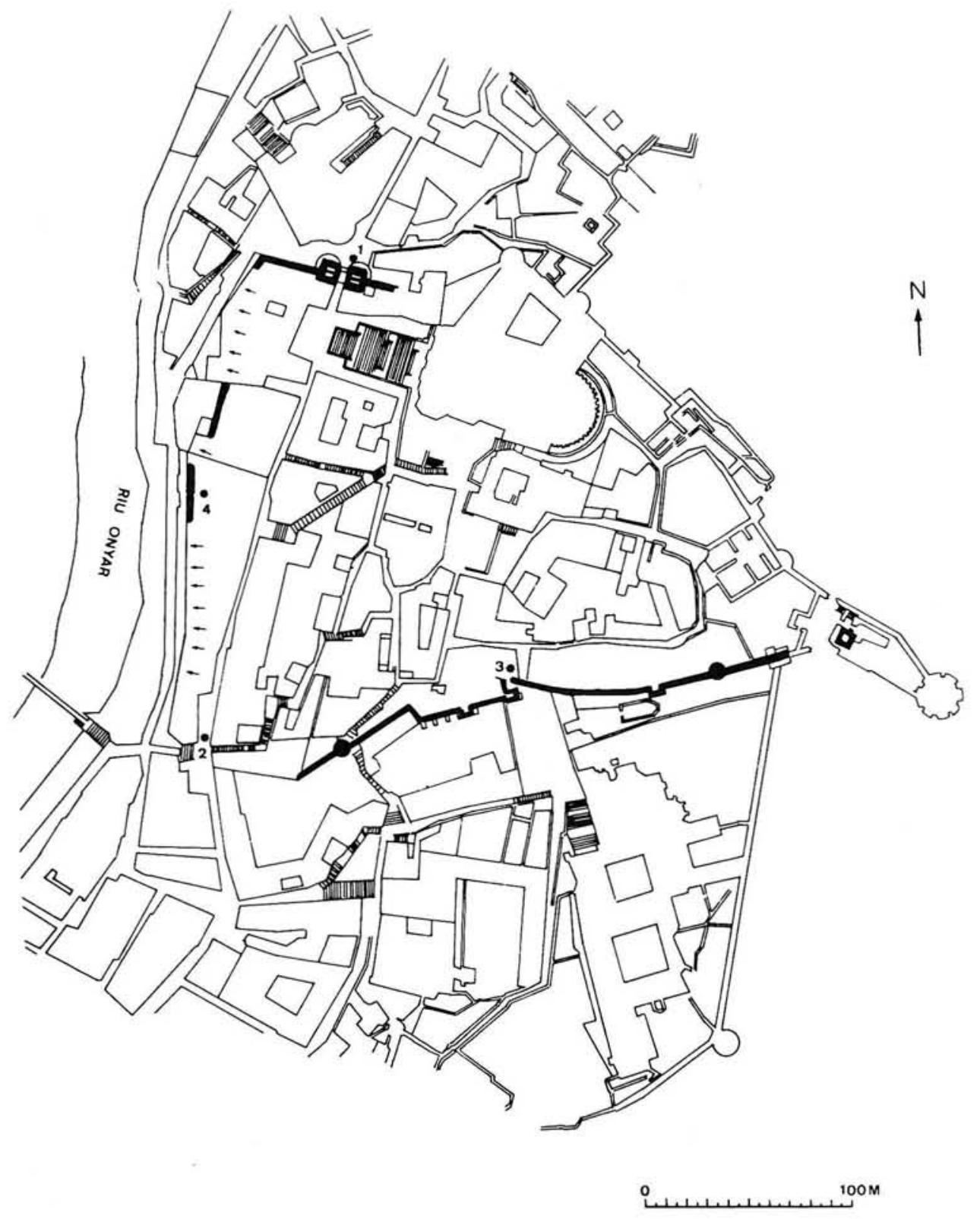

Planta de Gerunda (Nolla, 1987) 
cida como "Força Vella"-, que reaprovecha el antiguo recinto imperial. Sin embargo, su trazado y estructura originales -al menos en los que se refiere a las zonas inferiores de los muros- no parecen haber sufrido modificaciones sustanciales desde época romana.

El primer plano del recinto amurallado se lo debemos a Cazurro, que realizó diversas exploraciones en la ciudad durante el año 1910. Sus trabajos no llegaron a ver la luz pero fueron conocidos y empleados por Rahola en su obra de carácter general sobre la capital del principado, donde aparece una de las primeras descripciones de las murallas (Rahola, 1929, 65). También Bosch Gimpera había dedicado su atención a este tema algunos años antes (Bosch Gimpera, 1919, 257). El primer trabajo monográfico es el de Fick (Fick, 1930), seguido poco después por los de SerraRàfols, uno de los investigadores que más esfuerzos ha dedicado a aclarar distintos aspectos relacionados con las fortificaciones gerundenses (Serra-Rafols, 1927-31; 1941;1942 a; 1942 b; 1967). A este autor le debemos la descripción más completa realizada hasta la fecha del recinto amurallado tardorromano (Serra-Rafols, 1942 b). Las excavaciones llevadas a cabo por Riuro y Oliva en la llamada "Caserna d' Alemanys" durante los anios 1948-9 no han sido publicadas hasta hace pocos años por Nolla (Nolla, 1980). Este autor, que dedicó su Tesis Doctoral - aún inédica- al estudio de la Gerona romana (Nolla, 1977), ha centrado sus actividad en la muralla romana de la ciudad, consiguiendo, con su abundante producción bibliográfica, despejar muchas de las incógnitas planteadas sobre su datación, técnica constructiva y trazado, consideradas irresolubles hasta hace pócos afios (Nolla, 1978 a; 1978 b; 1979; 1979-80; 1987; Nolla y Nieto Prieto, 1979; Nolla y VV.AA., 1989; Nolla y Sagrera, 1990). Una completa bibliografia sobre las excavaciones y exploraciones llevadas a cabo en Gerona se encuentra en uno de los últimos trabajos de Nolla (Nolla, 1987, 16-7).

La antigua Gerunda ocupaba una colina rocosa de forma triangular situada en la confluencia del rio Onar y del arroyo Galligans. El punto más alto, elevado 60 metros sobre el nivel del terreno circundante, se localiza en el lado oriental, dominado por la Torre Gironella. Las pendientes del lado nororiental, abierto hacia el barranco del Galligans, son muy pronunciadas, mientras la colina desciende suavemente en dirección al río. El trazado de la muralla romana y medieval se adapta perfectamente a la topografia del terreno, adoptando una forma irregular, semejante a un triángulo, y extendiéndose a lo largo de aproximadamente $1 \mathrm{~km}$, lo que equivale a una superficie entre 5 y 6 has (SerraRafols, $1942 \mathrm{~b}, 114-6$ ). La fortificación está reforzada con torres cuadrangulares -torres del Telégrafo optico y del Colegio de la Sagrada Familia- y circulares - torres del lienzo de Las Aguilas y de la Escuela Pía (Serra-Rafols, 1942 b, 123-4). La torre cuadrangular del Colegio de la Sagrada Familia, la mejor conservada del recinto, arroja unas medidas de 3, 40 metros de proyección exterior y 6, 20 de frente, siendo su interior macizo (Serra-Rafols, 1942 b, 127). El cuerpo inferior de la Torre del Telégrafo óptico, situada en el extremo oriental de la muralla, corresponde también al proyecto romano (SerraRafols, 1942 b, 122). Menos convencido se encuentra Serra-Rafols del origen romano de las dos torres circulares de 7,70 metros de diámetro y 13 metros de altura, piso superior con ventanas de medio punto y diferente técnica constructiva (Serra-Rafols, 1942 b, 118 y 131).

Bajo la Torre Gironella, perteneciente a la fortaleza medieval y volada por los franceses en 1814, se encuentran los restos de una gran torre cuadrangular romana, de unos nueve metros de lado y de 7 a 8 metros de altura. Aunque ya diversos autores habian señalado su imbricación dentro del recinto amurallado romano (Fick, 1931, 266), las primeras excavaciones las realiza Serra-Rafols en 1930-1 y 1941-2, publicando poco después sus resultados (1927-31; 1942 a; 1942 b). Para este investigador dicha torre se encontraba aislada del resto de la muralla, dispuesta a la manera de una gran atalaya avanzada (Serra-Rafols, 1942 b, 121-2). Las excavaciones realizadas en 1973 por M. Oliva no fueton publicadas. Desde 1987 se vienen realizando exploraciones arqueológicas en el 
entorno de la misma, dirigidas por J. M. Nolla, que han aclatado de manera incontestable la unión entre el ángulo suroeste de la torre y el conjunto del perímetto amurallado, mientras la ausencia de muro de cierre en el ángulo contrario -el noroeste- le lleva a plantear la existencia de una puerta de la muralla en este sector, que estaría protegida por la propia torre (Nolla y VV.AA., 1989, 125-6).

Esta hipotética puerta, cuyos restos conseructivos altoimperiales se encontraron embutidos en los cimientos de la vecina Torre del Telégrafo durante la campaña de 1988 (Nolla y Sagrera, 1990), vendría a completar el panorama de las puertas de la muralla bajoimperial de Gerunda, de las que ya se conocían orras tres: el Portal de Sobreportes, al norte, y la Puerta "de la Força" o "del Correu Vell" y la Porta Rufina, al sur. De las dos primeras, correspondientes a los extremos del cardo maximus, por donde discurrfa la Via Augusta (Nolla, 1987, 76), tan sólo ha llegado hasta nosotros el llamado Portal de Sobreportes, de 3,70 metros de anchura (Nolla, 1987, 76) y flanqueado por dos torres cuadrangulares que sobresalian exteriormente unos tres metros, que se encuentran enmascaradas bajo torreones medievales semicirculares (Serra-Rafols, 1942 b, 133-4). Recientemente se han realizado excavaciones en la torre derecha, perteneciente a la "Casa Pastors" (Nolla, 1977; Nolla, 1978 a, 28-30; Nolla y Nieto Prieto, 1979). Las escasas noticias disponibles parecen apuntar en el sentido de que la puerta "de la Força", destruida en 1857, poséa una estructura muy parecida (Nolla, 1987, 77). La Puerta Rufina, abierta en la Plaza de Santo Domingo, fue identificada en 1930 por Serra-Rafols. En realidad se trata de una doble puerta en recodo, de unos dos metros de anchura y protegida por una torre cuadrada a su izquierda (Serra-Rafols, 1927-31, 76; Serra-Rafols, 1942 b, 125; Nolla, 1978 b). A estas tres entradas Serra-Rafols añadia una pequeña poterna localizada en la Casa Boschmonar (Serra-Rafols, 1941; 1942 b, 120), recientemente reinterpreada como una cloaca romana incorporada al recinto bajoimperial (Nolla y VV.AA., 1989, 113, nota 12).

En 1941 Serra Rafols encontró un gran arco de sillares de arenisca incorporado a un muro medieval de la Torre Gironella, al norte de la torre romana, que interpretó como una puerta tomana (Serra-Rafols, 1942). Nolla, algunos años más tarde, comprueba que su construcción corresponde a la misma época que el resto del muro - esto es, medieval-, aunque posiblemente los sillares fueron arrancados de una puerta romana cercana (Nolla y VV.AA., 1989, 120-1), tal vez la construcción tardía del Portal de Levante (Nolla y Nieto Prieto, 1990, 282).

Desde el punto de vista constructivo, los lienzos conservados de la muralla romana, especialmente los de Las Aguilas y la "Casa Pastors", presentan dos paramentos superpuestos muy diferentes y perfectamente definidos. La parte inferior de los muros está edificada con grandes bloques irregulares de piedra caliza de la zona, tallados de forma poligonal y calzados con piedras de menor tamaño, que forman hiladas más o menos rectas, adaptadas a la topografia del terreno (Serra-Rafols, $1942 \mathrm{~b}, 123$ ). Los investigadores han venido a llamar "ciclópeo" a este aparejo, que presenta numerosas similitudes con determinados sectores de las murallas de Ampurias, Tarragona y Ullastret, entre otras (Oliva, 1965, 91-2). Las excavaciones arqueológicas realizadas en la Torre del Telégrafo y en la Torre Gironella han permitido comprobar que los cimientos se asientan directamente sobre la roca madre y emplean el mismo sistema constructivo (Serra-Rafols, 1942 b, 122-3; Nolla y VVAA., 1979, 122).

Sobre este basamento se dispone el segundo paramento, consistente en hiladas regulares de sillares, tallados en arenisca de las canteras de Domeny, normalmente bien escuadrados y a veces con un ligero almohadillado. La anchura total de la muralla medieval alcanza entre 3 y 4 metros, suponiéndose una medida similar para la muralla romana (Serra-Rafols, $1942 \mathrm{~b}, 134$ ). El relleno interior debia consistir en piedras pequeñas, trabadas con tierra o mortero (Nolla, 1987, 75), a pesar de la opinión de Serra-Rafols proclive a un interior macizo (1942 b, 135). Carecemos de elementos de juicio sobre las partes altas de la muralla, muy reformadas durante la Edad Media. 
El doble paramento constructivo se comprueba asimismo en la torre romana excavada recientemente bajo la Torre Gironella (Nolla y VVAA., 1989, 121-2). Tradicionalmente fue interpretado como prueba irrefutable de la existencia de un primer recinto iberico, al que le correspondería el aparejo "ciclópeo", y un segundo recinto tardorromano, edificado directamente sobre el anterior en opus quadratum (Botet i Siso, 1909; Oliva, 1965; Serra-Rafols, 1927-31, 71; Serra-Rafols, 1942 b, 1 16-7). En 1967, este último autor expresa sus dudas sobre el carácter ibérico de las murallas ciclópeas (Serra-Rafols, 1967, 46-50). En 1972, la llamada excavación "Cuina", realizada en la Casa Pastors por M. Oliva, proporcionó los datos suficientes para aclarar el problema cronológico planteado por la muralla. Dicha excavación se centró en el relleno de una de las torres laterales del Portal de Sobreportes. Esta se asentaba directamente sobre la muralla ciclópea, a la que aparecian asociados materiales datables en la segunda mitad del siglo I a. C., concretamente entre los años 80- 70 a. C. (Nolla, 1978 a, 28-30). La primera muralla de Gerunda no sería por lo tanco indigena, sino tardorrepublicana, tal vez asociada a las guerras sertorianas (Nolla, 1979-80, 117 . 8). El relleno interno de la torre, sellado por un pavimento de opus signinum ha proporcionado datos inestimables sobre el momento de edificación de la muralla bajoimperial, que ruvo lugar, a juzgar por los restos cerámicos y numismáticos, encre el 260 y el $290 / 300 \mathrm{~d}$. C., posiblemente a partir del 284 (Nolla, 1978 b, 28; Nolla y Nieto Prieto, 1979, 282-3). La muralla tardía emplearía como basamento la parte inferior de los lienzos de la tardorrepublicana, que probablemente se encontraba en mal estado y fue necesario rehacer casi por completo (Nolla y VV.AA., 1989, 126). Nolla y Nieto relacionan la elevación de la muralla tardorromana con la probable destrucción de Gerona por parte de los franco-alemanes (Nolla y Nieto Prieto, 1979, 283).

Hasta el momento, los arqueólogos no han encontrado ningún dato que avale alguna actividad edilicia en la muralla durante la época altoimperial, a excepción de los restos constructivos del Portal de Levante, datados posiblemente en época augustea, y que fueron desmontados a finales del siglo III con motivo de la edificación de la muralla tardía, en cuyos cimientos se encontraron empleados. Desconocemos el motivo que llevó a este cambio estructural aunque, con toda probabilidad, fue sustituida por otra puerta de acuerdo con las nuevas necesidades urbanas, tal vez la empotrada en el muro medieval de la Torre Gironella (Nolla y Sagrera, 1990, 281-2).

Los recientes trabajos de Nolla -con la ayuda de otros investigadores- han proporcionado a la mutalla getundense tal vez la datación más ajustada y fiable entre todos los recintos fortificados bajoimperiales hispanos, aunque también en este caso seguimos moviéndonos dentro de unos amplios márgenes cronológicos.

\section{Emporiae (Ampurias)}

La arqueología no proporciona ninguna evidencia sobre la existencia de un recinto bajoimperial en Ampurias, cuya evolución desde el punto de vista defensivo resulta por otra parte bastante bien conocida (Almagro Basch, 1962; Aquilue y VVAA., 1984; San Marti, Castafier y Tremoleda, 1988). Sin embargo, hace pocos años, Nieto Prieto ha formulado la hipótesis de que la muralla que rodea la localidad de San Martí d'Empúries, tradicionalmente considerada la muralla griega de la antigua Palaiapolis (Almagro Basch, 1964, 97-8), se trate en realidad de una muralla bajoimperial construida ex-novo o reedificada sobre la preexistente griega (Nieto Prieto, 1981, 47-9). A esta conclusión le lleva la concentración del material cerámico más moderno en el solar de San Martí d'Empúries, que hablaría de una despoblación de la ciudad greco-romana y un traslado de sus habitantes hacia la elevación rocosa de la Palaiapolis, así como el reaprovechamiento de frag- 
mentos de columnas (Almagro Basch, 1964, 8) dentro de la estructura de sillares areniscos de la muralla. Hasta el momento esta hipótesis permanece sin demostrar y bajo ningún concepto podemos clasificar este recinto dentro de los tardortomanos.

\section{Tarraco (Tarragona)}

Gracias sobre a todo a los trabajos realizados por Serra Vilaró (Serra Vilaró, 1949) y Hauschild (1979, entre otros), no existe ninguna duda sobre la cronología tardorrepublicana de este recinto amurallado. Sin embargo, el potens arce mencionado por Ausonio (Ordo Urbitum Nobilitum XI, 82-3), debia seguir operativo durante el Bajo Imperio. Desconocemos como fue afectada esta inexpugnable fortaleza por la incursión de los franco-alemanes que, según las fuentes, destruyeron la ciudad, pero todo apunta a su conservación en buenas condiciones. En 1984-5 Hauschild da cuenta de la existencia de reformas parciales en la cámara superior de la Torre de la Minerva, datadas por los materiales a comienzos del siglo $\mathrm{V}$, e incluso en un momento algo más avanzado (Hauschild, 1984-5, 26; Vegas, 1984-5, 54). Hauschild plantea la hipótesis de que estas reformas tengan algo que ver con la invasión de los bárbaros a principios del V o con la toma de la ciudad por el rey visigodo Eurico el $476 \mathrm{~d}$. C. Estas modificaciones bajoimperiales no han sido constatadas hasta el momento en ningún otro lugar del perímetro amurallado, motivo por el cual no nos podemos pronunciar sobre su alcance real.

\section{Ilerda (Lérida)}

Aunque no queda huella alguna del supuesto recinto bajoimperial de la antigua Ilerda, los cronistas y eruditos de la ciudad han venido manteniendo tradicionalmente su existencia. Para Balil, "La significación de la ciudad como plaza fuerte medieval induce a pensar en un posible recinto del Bajo Imperio" (Balil, 1960, 187). A partir de textos y descripciones antiguas de escasa fiabilidad, Lara Peinado ha definido hace algunos años el perímetro de la muralla, de planta irregular, que ocuparía la mayor parte de la colina de la Seo, hasta orillas del río Segre (Lara Peinado, 1970, 634). Según este mismo autor, Pita Mercé identifico en 1942 la estructura de la muralla bajo las casas de la plaza de España, la plaza de la Pahería y la calle Mayor, describiéndola como una construcción realizada con grandes bloques cuadrados y reforzada con torres de planta rectangular (Lara Peinado, 1973, 108-10). Las similitudes de la Puerta de "Boters", derribada el siglo pasado y conocida a través de un dibujo de Laborde, con la también desaparecida Puerta de la Cárcel de las murallas de Barcino, le llevan a Balil a plantear su posible origen romano (Balil, 1960, 187-8), atribución defendida por Lara Peinado (Lara Peinado, 1973, 108). Este mismo autor defiende incluso la existencia de una segunda línea de fortificación en la parte alta de la ciudad, con la misma estructura y técnica constructiva que la primera, que se habría levantado sobre la antigua acrópolis ilergete durante la segunda mitad del siglo III (Lara Peinado, 1973, 108-10). Otros investigadores han mantenido asimismo una datación bajoimperial para el recinto fortificado de Lérida (Arce, 1982,96).

Sin embargo, la inconsistencia de los argumentos empleados para la datación de las murallas ilerdenses en época tardorromana ha sido señalada recientemente por Pérez i Almoguera, para quien se trata de hipótesis sin base objetiva (Pérez i Almoguera, 1984, 49). Esto no significa que debamos aceptar como ciertos los calificativos de deiectae ruinae que Ausonio (Epistularum XXIX, 50-61 y XXIX, 220- 5) dedica a la Parrula Ilerda de finales del IV, recurso retórico que la arqueologia está contestando convenientemente (Arce, 1982, 88-9; Lara Peinado, 1973, entre otros). 


\section{Caesaraugusta (Zaragoza)}

Nuestro conocimiento acerca de las murallas bajoimperiales de Caesaraugusta es mucho más limitado que el que disfrutamos respecto a recintos como el de Barcelona o Gerona. Sin embargo, los escasos restos que han legado hasta nosotros constituyen pruebas fehacientes de su existencia e importancia. Tan sólo dos lienzos de muralla resultan visibles en la trama urbana: el sector del Convento del Sepulcro y el de San Juan de los Panetes, aunque se ha constatado su presencia en otros puntos de la misma (Beltrán Lloris y VV.AA., 1985, 90, 96 y 100). Los estudios sobre su fase tardía son antiguos y más descriptivos que arqueológicos, limitándose a los de Richmond (Richmond, 1931), De la Figuera (De la Figuera, 1934) e Iñiguez (Iniguez, 1959), a los que hay que sumar las exploraciones y sondeos realizados por Beltran Lloris en la fortificación altoimperial, que en su mayorfa aportan interesantes datos sobre aquella (Beltrán Lloris, 1969, 418-20; 1970; 1976; Beltrán Lloris y VV.AA, 1980).

Las murallas tardorromanas se adaptan, al igual que las altoimperiales, a la planta rigurosamente ortogonal de la colonia romana, establecida sobre un terreno llano a orillas del Ebro. Iñiguez las describe como un rectángulo con dos ángulos achaflanados y otros dos redondeados, que constaría de cuatro puertas en los extremos del cardo y el decumano máximos (Iñiguez, 1959, 254), ninguna de las cuales ha llegado hasta nosotros, a pesar de que conocemos su existencia por descripciones antiguas y testos epigráficos (Galve y Magallón, 1975, 214-17). El recinto amurallado, que abarcaba una superficie de 60 has. -unos 3500 metros de perímetro-, estaba reforzado con torres semicirculares, de las cuales se conocen dos en el Convento del Sepulcro y tres en el lienzo de San Juan de los Panetes. Su radio varía entre los 3,70 y los 4,15 metros. Están separadas por lienzos que miden entre 13 y 14, 85 metros. Al menos en el sector de San Juan de los Panetes, los torreones se alzan sobre el suelo virgen sin cimentación (Iñiguez, 1959, 258-62). Junto al tercer torreón de San Juan de los Panetes se hallaron restos de una estructura adosada a la muralla, que en este punto reduce su anchura (Ifiguez, 1959, 266). El conjunto es de difícil interpretación.

Iniguez documentaba dos técnicas constructivas diferentes en la estructura del lienzo de muraIla de San Juan de los Panetes: la parte interna, de unos 3,20 metros de espesor, era de hormigón; la parte externa está realizada en sillería tegular, con bloques almohadillados de arenisca en las hiladas inferiores y alabastro en las superiores, dispuestos siempre "a soga" y trabados con un mortero muy ligero que no llegó a fraguar. El núcleo de esta sección externa estaba compuesto de grandes bloques de piedra unidos con tierra. Entre los sillares del paramento externo y del relleno se encuentran numerosos materiales arquitectónicos y epigráficos reutilizados. La anchura de este cuerpo externo es de 3, 22 metros, aumentando hasta treinta centímetros en la base, lo que le confiere a la muralla un espesor total de 6,42 metros. Los dos muros están adosados pero parecen construidos en diferentes momentos (Iniguez, 1959, 262). El muro de hormigón correspondería al recinto altoimperial, al igutal que los torreones de mayor tamaño hallados bajo la primera torre de San Juan de los Panetes (lñiguez, 1959, 264) y en el ángulo formado por el paseo de Echegaray y la plaza de Tenerías (Beltrán Lloris, 1976; Beltrán Lloris y VV.AA., 1980, 212-6). Este autor data este primer recinto en época fundacional.

En un momento posterior, no bien definido estratigráficamente, el primer recinto debió sufrit importantes modificaciones que determinaron el arrasamiento de al menos algunas de sus torres, sustituidas por otras de menores dimensiones, mientras se recrecían los lienzos augusteos, doblando su espesor (Belrrán Lloris, 1976, 97-8). La única fecha post quem para la edificación del segundo tecinto viene dada por las importantes obras de aterrazamiento y acondionamiento del terreno llevadas a cabo en época flavia (Beltrán Lloris 1969, 432-3; Beltrán Lloris y 
VV.AA, 1980, 215), que determinaron la creación de un gran campo subterráneo de ánforas testimoniado en el Convento del Sepulcro (De la Figuèrz, 1934, 159; Iñiguez, 1959, 259-60), preparación sobre la que se dispone la muralla tardía. La fecha de edificación de ésta muralla que, siguiendo una tendencia generalizada, la mayoría de los autores relaciona con la invasión de los franco-alemanes (Richmond, 1931, 98; Iñiguez, 1959, 267) resulta por el momento imposible de precisar. Lo mismo podemos decir de la relación topográfica y estructural entre los dos tecintos.

\section{Sos del Rey Católico}

Tan sólo Taracena alude al carácter tardorromano de las murallas de un despoblado existente junto a Sos del Rey Católico, identificado hipotéticamente como la Nemanturissa romana (Taracena, 1949, 438). Este autor senala de forma escueta su semejanza con las de Uxama, a pesar de su menor tamaño. Balil, algunos años más tarde la recoge en su catálogo de fortificaciones bajoimperiales, sin formular ninguna opinión al respecto (Baliil, 1960, 188-9). No conocemos nada nuevo acerca de este recinto, sobre cuya cronología albergamos serias dudas.

\section{Ologitum (Olite)}

El origen romano del recinto amurallado de la ciudad de Olite, según San Isidoro fundada por el rey visigodo Suintila el año 621, ya fue apuntado en 1947 por Taracena y Vázquez de Parga (Taracena y Vázquez de Parga, 1947, 115), aunque el primero de ellos no la incluye entre las fortificaciones tardias (Taracena, 1949). Balil apunta en 1961 la posibilidad de que se trate de una muralla bajoimperial (Balil, 1961, 125). Las murallas de esta localidad navarra han sido descritas recientemente por Jusué (Jusué, 1985) y Ramos Aguirre (Ramos Aguirre, 1987).

Jusué considera que el sector septentrional de la potente muralla edificada en época medieval, corresponde en realidad a un recinto tomano de planta trapezoidal reforzado con torres cuadradas dispuestas cada 30 metros, cuyos restos aún resultan visibles en doce de las torres y en algún fragmento de lienzo. El perímetro de este "oppidum", unos 600 metros, define una superficie cercana a las 2 has. En su costado oriental, se elevaba una construcción tectangular enmarcada por cuatro torres y ocupada actualmente por el Parador Nacional, interptetada como un Praetorium (Jusue, 1985, 229-35). La técnica constructiva, a base de sillares bien escuadrados y almohadillados, dispuestos en opus quadratum sin argamasa y con un relleno interno de pequeñas piedras trabajas con mortero, le llevan a datar esta construcción en época altoimperial (Jusue, 1985, 235). Ramos Aguirre confirma esta datación, pero distingue una primera fase constructiva en época sertoriana a la que correspondería el pretorio. El resto del recinto es una ampliación posterior, posiblemente augustea y de alguna manera relacionada con las guerras cántabras (Ramos Aguirre, 579-80).

La carencia de excavaciones arqueológicas en el recinto amurallado y el empleo de argumentos exclusivamente históricos y edilicios, no ofrecen garantías suficientes como para aceptar la fecha propuesta con un mínimo de certeza. Por otra parte, la anchura de las murallas -unos 3,5 merrosy su técnica constructiva no se alejan mucho de las características de las murallas bajoimperiales hispanas. Restaría además aclarar la supuesta fundación goda mantenida por las fuentes históricas. Mientras no se realicen estudios auténticamente arqueológicos resultará muy difícil pronunciarse sobre la cronología del recinto de Olite. 


\section{Pompaelo (Pamplona)}

Los datos arqueológicos no permiten hasta el momento avalar la existencia de un recinto bajoimperial en la antigua Pompaelo, que encerratía una extension rectangular de $500 \times 300$ metros de lado, correspondiente a la antigua ciudad medieval. Taracena y Vázquez de Parga recogen una noticia de 1607 transmitida por Sandoval, que hace referencia al hallazgo de cimientos de una torre de la antigua muralla. Ellos mismos documentaron un supuesto lienzo de muralla en un sótano de la calle Chapitela del cual aseguraban "no es posible por ahora asignar fecha imperial precisa a tales restos" (Taracena y Vázquez de Parga, 1947, 115-7). Este muro no se ha conservado hasta nuestros días (Mezquíriz, 1976, 190). Los trabajos de esta investigadora en la capital navarra, no han revelado testo alguno que pudiera corresponder al recinto fortificado, aunque sí abundante material de época tardorromana (Mezquiriz, 1958; 1978). Mezquíriz admite que la ciudad pudo tener una muralla en el siglo III (Mezquíriz, 1976, 190).

Los datos literarios plantean en este caso una contradicción de dificil respuesta. La supuesta carta de Honorio dirigida a la guarnición de Pompaelo, conocida como De Laude Pampilone Epistola y recogido en el Códice de Roda, describe una ciudad amurallada de 4400 metros de perímetro, reforzada con 67 torres separadas por lienzos de 47 metros. Las 120 has. de superficie resultantes parecen a todas luces excesivas para una ciudad hispana. La mayoría de los investigadores ha considerado que el nombre de Pampilona tal vez se trata de un error o una falsificación, y que dicho texto harfa referencia a alguna ciudad gala (Lacarra, 1945, 266; Taracena y V. de Parga, 1947, 118).

\section{Calagurris (Calahorra)}

La presencia en la colonia romana de Calagutris de una muralla romana ha sido defendida recientemente por Gómez-Pantoja, que recoge la aparición de una estructura realizada con dos paramentos de sillares de buen tamaño unidos por tirantes y relleno interno de cascote, localizada en unos desmontes al norte de la ciudad actual. El autor interpreta esta construcción como restos de una muralla de planta trapezoidal, cuyos torreones cuadrangulares ya habían sido mencionados en alguna noticia escrita (Gómez- Pantoja, 1976, 187). Aunque la excavación de la muralla proporcionó abundante material del siglo I d. C., Gómez-Pantoja no descarta la posibilidad de que se trate de una muralla construida en la segunda mitad del siglo III debido al temor a las incursiones germanas (Gómez-Pantoja, 1976, 187). Sin tener en cuenta que carecemos de dato arqueológico alguno que avale esta datación, a no ser en el terrero de las meras especulaciones, Arce ha defendido recientemente su existencia (Arce, 1982, 96).

\section{Inestrillas (Aguilar del ró Alhama, La Rioja)}

A diferencia de otros hipotéticos recintos amurallados bajoimperiales, en Inestrillas está suficientemente constatada, al menos desde un punto de vista tipológico, la existencia de una fase constructiva de este momento. Taracena fue el primero en explorar las murallas celtibero-romanas de Inestrillas, localidad que identificó como Contrebia Leukade (Taracena, 1926). Durante los afios 1934 y 1935 este investigador realiza excavaciones en la misma (Taracena, 1942), que han sido continuadas con varios sondeos y un estudio más completo en época reciente (Hernández, Vera, 1978 y, en especial, Hernández Vera, 1982). 
Las ruinas de Inestrillas ocupan un elevado cerro cortado a pico por el río Alhama en su vertiente oeste. La topografía del terreno hace absolutamente innecesaria la construcción de fortificaciones en este sector, mientras que por los otros tres lados, la ciudad se rodeo de una potente muralla y un foso de unos ocho metros de anchura por otros tantos de profundidad excavado en la roca. La fortificación adopta por lo tanto una planta semicircular, formando ángulos obtusos, y encerrando una superficie de 12 has. (Taracena, 1926, 138; Taracena, 1942, 23).

El análisis de la planta y la técnica edilicia ha revelado la existencia de dos periodos constructivos perfectamente diferenciados: los lienzos de los lados este y sur, de entre 2,5 y 4 metros de anchura, construidos con piedra caliza del propio yacimiento en forma de tosco sillarejo y relleno interno de tierra y piedras, responde a las características de una muralla celtibérica. A este periodo le correspondería asimismo el foso (Taracena, 1942, 23; Hernández Vera, 1982, 122-3); en época romana el recinto amurallado se cierra por el lado nororiental con un lienzo reforzado por seis torres semicirculares de 4 metros de radio, dispuestas a distancias irregulares. Entre las dos más orientales se abre una puerta de un sólo vano. La técnica constructiva de esta muralla es mucho más cuidada que la anterior, constando de dos paramentos verticales y un relleno interno de capas alternas de piedras y tierra. En la parte inferior de los muros se emplean sillares de caliza bien escuadrados, aunque de distintos tamaños, unidos con mortero. En las partes altas los sillares de arenisca alternan con otros más pequeños de caliza, unidos a hueso.
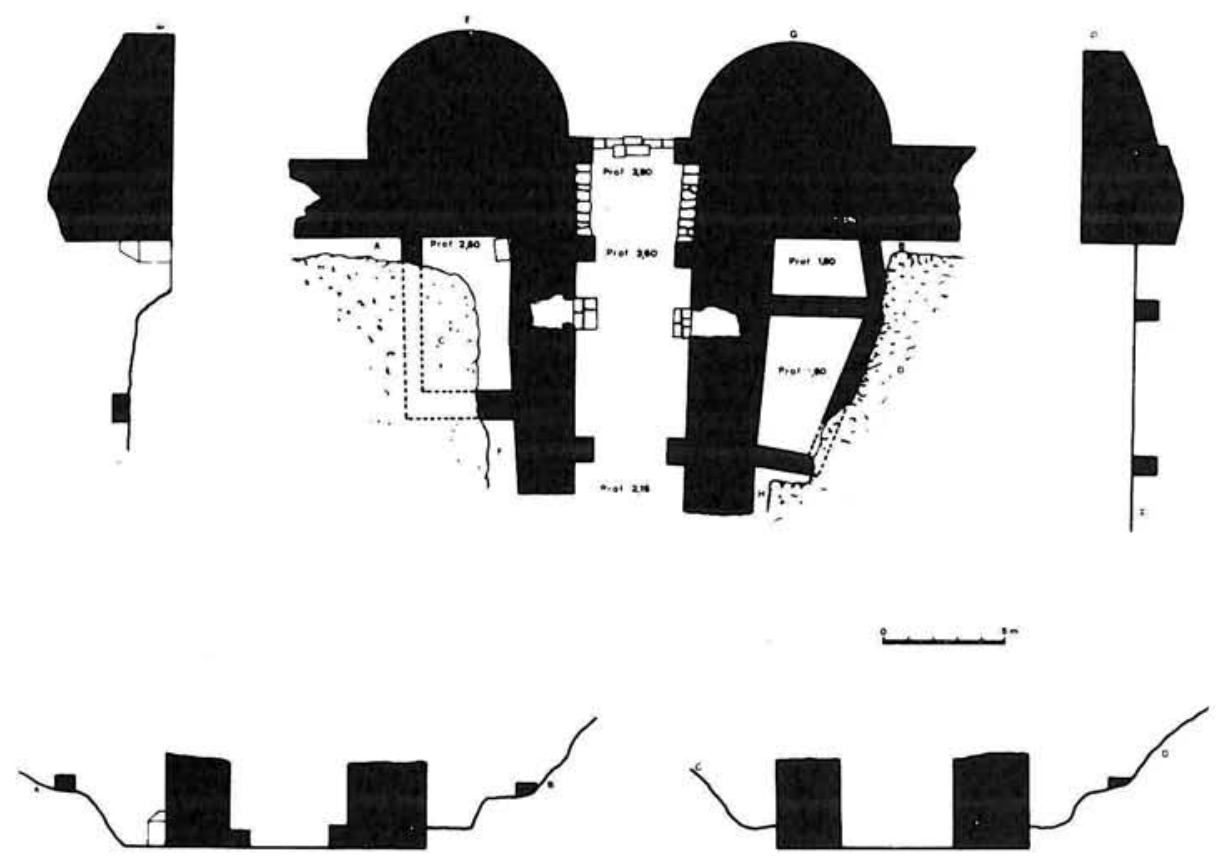

Puerta de İnestrillas (Hernández Vera, 1982) 
Entre ellos se encuentran algunos elementos reutilizados. La anchura total del conjunto es de unos tres metros y en algunas partes se conservan hasta cuatro metros de altura (Hernández Vera, 1982, 127-9). Este autor no descarta que la muralla celtibérica sufriera algún tipo de remodelación en esta época, que no afectaría de forma determinante a su estructura original (Hernández Vera, 1982, 120).

La técnica constructiva llevó a Taracena a proponer una dacación de los siglos III-IV para la muralla romana (Taracena, 1926, 140-2). El hallazgo, años más tarde, de una inscripción de los siglos I-II reutilizada en la edificación de la puerta le proporcionó una fecha past quem acorde con su hipótesis inicial (Taracena, 1942, 23). La reinterpretación de Hernández Vera no ha modificado de forma sustancial las opiniones de Taracena. El motivo de la refortificación de este recinto en época bajoimperial, momento en que la antigua ciudad indígena se encontraba casi abandonada, habria que buscarlo en razones de f́ndole estratégica tales como la protección de uno de los principales caminos hacia la Meseta ante la supuesta segunda oleada de invasores francos, que penetrarían por los Pirineos Occidentales entre el 276 y el 285 d. C. (Hernández Vera, 1982, 135-6). Este autor llega a plantear la existencia de una guarnición romana en este punto.

Sin negar el indudable esfuerzo de interpretación realizado por Hernández Vera, la carencia de excavaciones metodológicas que puedan revestir de la adecuada argumentación a sus hipótesis, proyecta significativas sombras sobre su armazón histórico, basado en apreciaciones de índole edilicia. La comprobación estratigráfica de las murallas bajoimperiales de Inestrillas aún está por realizat.

\section{Monte Cantabria (Logrono)}

La histórica ciudad de Cantabria fue localizada por Taracena en un cerro siruado frente a Logroño (Taracena, 1942, 35-7), en cuyo ángulo suroeste localizó un recinto defensivo de planta rectangular, con 140 metros de eje mayor y torreones semicirculares cada 30 metros. Este autor lo clasifica como bajoimperial (Taracena, 1949, 439), atribución que mantiene Balil ańos más tarde (Balil, 1960, 191). En 1955 Fernández de Avilés publica los resultados parciales de sus excavaciones, realizadas diez afios antes, confirmando la existencia de una muralla con planta de polígono irregular de unas 1, 68 has. con 11 torres situadas a distancias de 25 a 29 metros, edificada en mampostería careada al exterior y algunos sillares aislados. El espesor de la misma variaba significativamente según los sectores, en uno de los cuales se localizó una puerta flanqueada por torreones (Fernández de Avilés, 1955, 332-3). En cuanto a la cronología de este recinto, Fernández de Avilés se ratificaba en la opinión de Taracena, aunque apuntaba por primera vez la hipótesis de un origen celtibérico (Fernández de Avilés, 1955, 334). Los trabajos desarrollados en 1977 por Pérez Arrondo alejan la posibilidad de una datación bajoimperial para el recinto de Monte Cantabria, sin lugar a dudas perteneciente a un oppidum celtibérico, aunque el autor no parece descartar una posible reocupación tardorromana de las estructuras defensivas anteriores (Pérez Arrondo, 1979, 76). La comprobación de esto último está sujeta a futuras excavaciones.

\section{Iruấa (Alava)}

Desde mediados del siglo XIX se vienen realizando exploraciones y sondeos en el despoblado romano existente junto a Iruña. Como en tantas ocasiones, a través de las noticias parciales transmitidas por los eruditos decimonónicos, ya se conocían algunos datos sobre sus murallas y puertas. Las primeras excavaciones arqueológicas realizadas con una metodología científica, fue- 
ron las de G. Nieto Gallo, desarrolladas entre los años 1949 y 1954 que, en buena medida, se centraron en las fortificaciones (Nieto Gailo, 1958). Desde esta fecha, tan sólo Elorza ha tratado con cierta extensión el tema, aunque este investigador no llegó a realizar excavaciones en el yacimiento (Elorza, 1972). Recientemente, un conjunto de arqueólogos ha retomado las excavaciones en el yacimiento de Iruña, aunque no en el sector de la muralla (Gil Zubillaga y VV. AA., 1991). No nos queremos detener demasiado en la descripción de este recinto fortificado, del cual uno de nosotros se ha ocupado muy recientemente (Morillo, 1991, 176).

La muralla de Iruña, yacimiento emplazado en un cerro circundado por el río Zadorra y a poca distancia de la capital alavesa, ha llegado hasta nosotros en bastante buenas condiciones, si bien los trabajos de Nieto Gallo sólo pusieron al descubierto algo menos de la mitad de sus aproximadamente 1200 metros de perímetro -entre 8 y 12 has.- (Balil, 1960, 189-91). Su planta es irregular, realizada mediante lienzos rectos de muro y reforzada con torreones cuadrados y semicirculares. Nieto Gallo documentó dos sectores muy diferentes desde el punto de vista constructivo: el sector occidental, construido con lajas unidas con argamasa, y el sector meridional, realizado en opus quadratum con sillates bien escuadrados. El relleno de lajas y mortero parece ser común a ambos sectores, al igual que la inclusión de materiales reutilizados dentro de la estructura de los muros, especialmente en el paramento interno, mucho menos cuidado. La anchura de los muros varía entre 4 y 5, 40 metros, mientras su altura alcanza los 8 metros en algunos puntos, llegando presumiblemente a 12. Las partes altas de las torres meridionales, edificadas en opus quadratum al igual que los lienzos de este sector, debieron emplear las lajas por encima de los 2,5 metros. La muralla se asentó directamente sobre la toca virgen, sin cimientación (Nieto Gallo, 1958, 119-34).

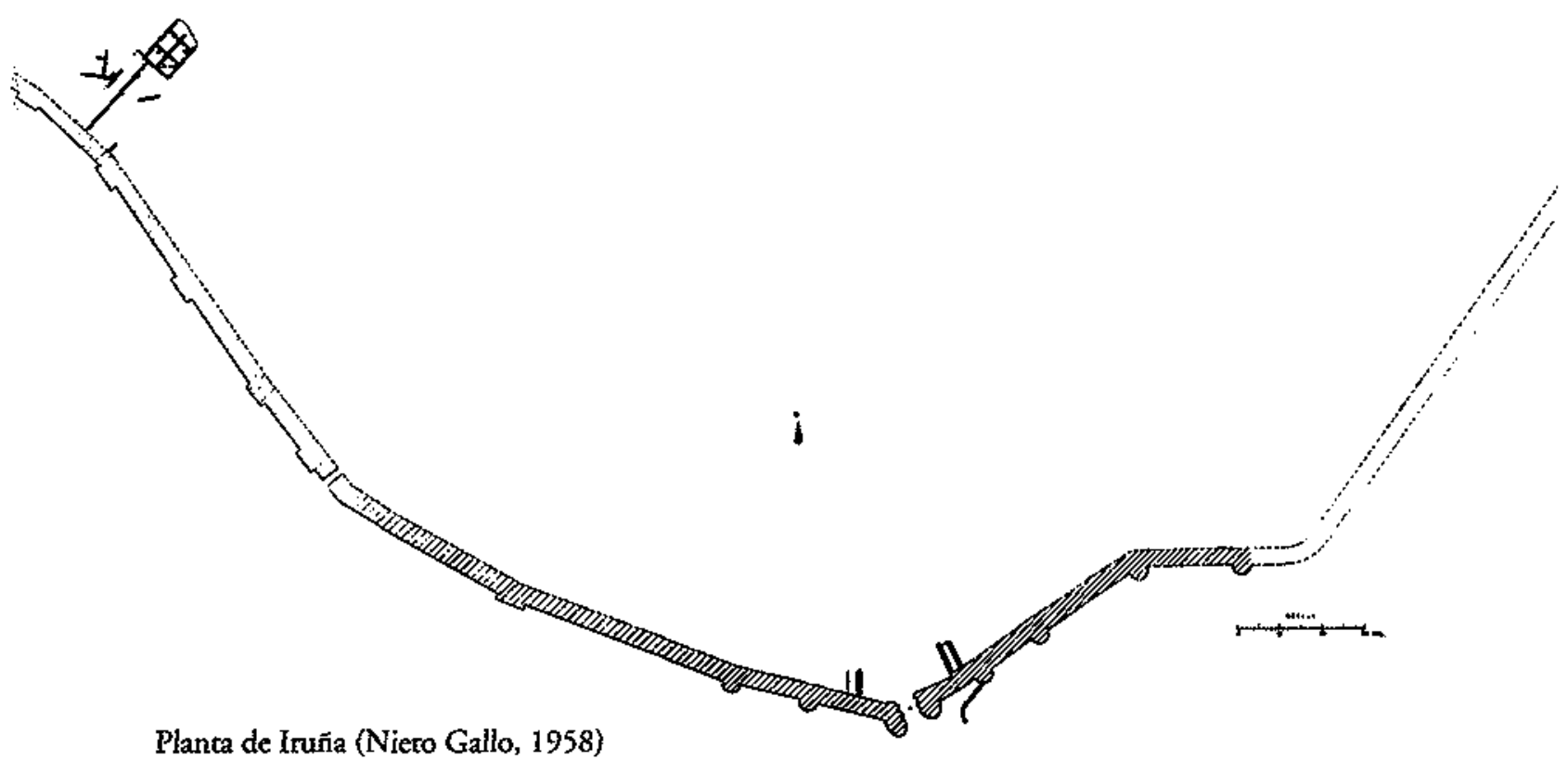


A esta dualidad constructiva desde el punto de vista técnico, le corresponde una dualidad en el tipo de planta de las torres de refuerzo. Estas adoptan una forma cuadrada en el sector occidental, mientras que en el lado meridional presentan una planta semicircular, con algo más de 8 metros de circunferencia externa. Tanto en uno, como en otro sector, las distancias entre los torreones son irregulares (Nieto Gallo, 1958, 119-40). En el sector meridional se abre una puerta dispuesta en eje y protegida con dos torres de flanqueo semicirculares, que constituyen un conjunto bastante imponente, construido con silleria bastante cuidada unida sin argamasa. Su profundidad es de 8 metros. En el lienzo suroeste se encuentra una pequeña poterna (Nieto Gallo, 1958, 137-9).

Taracena (Taracena, 1949, 439) y Balil (Balil, 1960, 189-91), basándose en la estructura y la técnica constructiva de las murallas de Iruña, incluyeron éstas dentro de las fortificaciones urbanas bajoimperiales. El hallazgo de restos epigtáficos reutilizados en la construcción de la muralla, así como materiales de la segunda mitad del siglo III junto a los sillares más bajos de la estructura, proporcionaron a Nieto Gallo en término post quem adecuado para datar la elevación de la muralla en la segunda mitad de este siglo, tal vez por causa de las invasiones germanas (Nieto Gallo, 1958, 143). Sin embargo, el abandono del recinto a partir de mediados del siglo IV, demostrado por la ausencia de materiales arqueológicos posteriores a este fecha, le hacen dudar de la posible identificación del recinto con Veleia, asiento según la Notitia Dignitatum (XIII, 1, 32) de la Cohors I Gallica a principios del siglo V (Nieto Gallo, 1958, 1489 y 225). Recientemente, Elorza, a partir de una reinterpretación de los restos arqueológicos, retrasa la construcción de las mutallas hasta comienzos del siglo IV y la perduración del hábitat durante todo este siglo (Elorza, 1972, 191-3).

En el estado actual de nuestros conocimientos, la cronología bajoimperial del recinto fortificado de Iruña no ofrece excesivas dudas, a pesar de que carezcamos de argumentos suficientes para proponer una datación más ajustada. En cualquier caso siguen existiendo puntos oscuros, como es el empleo de diferente técnica constructiva en dos sectores de la muralla, que podrían indicar la existencia de al menos dos fases constructivas. Por otra parte, la convivencia dentro de un mismo recinto de torres de refuerzo cuadradas y semicirculares resulta un hecho bastante poco común dentro de las fortificaciones bajoimpetiales hispanas. Esperamos que los nuevos proyectos de investigación emprendidos aporten nuevos datos.

\section{Monte Cildá (Olleros de Pisuerga, Palencia)}

El yacimiento de Monte Cildá ocupa una plataforma rocosa cortada por el cauce del río Pisuerga, que define profundos acantilados por todos sus lados a excepción del norte, donde se elevó una potente muralla defensiva. Esta delimita un espacio cercano a las 13 has. R. Moro, buscando el material epigráfico reutilizado en su construcción, desmontó parte de esta obra a finales del siglo pasado (Moro, 1891). Durante los años 1963 a 1969, Garcia Guinea, apoyado por un amplio equipo, realizó excavaciones en el área de la muralla, que terminaron con el descubrimiento de su estructura completa (García Guinea, González Echegaray y San Miguel Ruiz, 1966; García Guinea, Iglesias Gil y Caloca, 1973).

Los lienzos de la muralla siguen una dirección este-oeste, con varios quiebros en su recorrido, certando el lado septentrional del cerro. Está reforzada con 6 torres cuadrangulares, colocadas a intervalos irregulares. Las dimensiones de las torres son asimismo variables, aunque las más comunes se encuentran en torno a los 6 metros de frente y algo menos de 3 de espesor - 
torres I, II y IV- (García Guinea y V.V.A.A, 1966, 25-7). Dos de estos torreones -torres V y VI- protegen una puerta en el extremo occidental. La torre número III también parece construida en función de la defensa de una entrada, cuya interpretación es más problemática (García Guinea y VV.AA., 1973, 36).

Las excavaciones del ángulo noreste revelaron la existencia de dos lienzos adosados de diferente aparejo, con un telleno interno de piedras unidas con argamasa. El paramento interno estaba realizado con losas calizas no escuadradas, mientras el externo presentaba un aparejo de sillería perfectamente escuadrada, dispuesta en hiladas regulares. La muralla se asienta directamente sobre la roca del suelo, sin huellas de cimentación. La altura de los lienzos sería de unos tres metros, y a 1 , 55 metros del suelo correría un camino de ronda (Garcia Guinea y VV.AA., 1973, 25-7). El sector occidental, a partir de la llamada torte IV, emplea exclusivamente la caliza como material constructivo (García Guinea y VV.AA, 1973, 36). La publicación no informa en ningún momento de la anchura de la muralla, aunque afirma que este dato pudo comprobarse (Garcia Guinea y VV.AA, 1966, 25). En el paramento externo de la muralla son extremadamente abundantes los sillares y estelas funerarias reutilizadas.

Los excavadores han considerado que los dos paramentos constructivos con diferente estructura obedecen a la existencia de dos fases constructivas. El paramento interno correspondería a una muralla elevada durante el siglo III, posiblemente por causa de las primeras invasiones de pueblos germánicos. Ante las nuevas amenazas de comienzos del V, la muralla inicial resultaba insuficiente y se edificaría otra nueva, correspondiente al paramento externo. El centro de su argumentación reside , tanto en los materiales hallados en el nivel correspondiente a la construcción de la estructura defensiva, como en el hecho de que una obra del siglo III no hubiera empleado en su construcción las piedras de una necrópolis coetánea, restos que aparecen embutidos en el muro exterior (García Guinea y VV.AA, 1966, 24-5 y 27). Años más tarde, Balil ha planteado la posibilidad de que se trate de una muralla visigoda (Balil, 1970, 610).

A pesar de que Monte Cildá es uno de los pocos recintos tardortomanos excavados en toda su extensión, las murallas de Monte Cildá no dejan de plantear cuestiones de difícil respuesta, algunas de ellas causadas simplemente por cierta confusión existente en la bibliografia específica. Resulta complicado aceptar la existencia de dos amurallamientos sucesivos en un periodo de poco más de un siglo. La supuesta muralla edificada en el siglo III, que sólo fue constatada en el ángulo oriental de la fortificación, resulta aún más dudosa a la luz de la total ausencia de materiales en el yacimiento entre los siglos II y IV, síntoma, según los investigadores, de un traslado de la población al pie del cerro (García Guinea y VV.AA., 1973, 45-6).

\section{PROVINCIA CARTHAGINENSIS}

Pollentia (Alcudia, Baleares)

Ninguna publicación moderna sobre este yacimiento mallorquin hace referencia a las características técnicas y constructivas de la muralla descubierta en la zona de Sá Portela (Arribas, Tarradell y Woods, 1973; Arribas, Tarradell y Woods, 1978). En 1978 Tarradell, tras comprobar arqueológicamente la importancia de las destrucciones sufridas por Pollentia en el siglo IIl corrige sus primeras impresiones sobre la muralla, considerándola de la segunda mitad de este siglo, ante el hecho evidente de que amortiza construcciones destruidas por la invasión bárbara (Tarradell, 1978 a, 44). Este término post quem fue confirmado en la excavación del relleno de la muralla (Tarradell, 1977, 
28). En una publicación posterior, el autor reafirma el carácter tardío de la obra defensiva (Arribas y Tarradell, 1987, 123), cuyos detalles aún no los conocemos en profundidad.

En 1983, Arribas publica interesantes reflexiones sobre el perfmetro de la muralla (Arribas, $1983,40-1$ ), sin aportar ninguna novedad sobre su cronologia o estructura.

En resumen, podemos afirmar que el estudio de la muralla de Pollentia presenta graves lagunas en la bibliografia al respecto, como es la carencia de una descripción pormenorizada de la misma y de una datación más aproximada que el simple término post quem.

\section{Carthago Nova (Cartagena)}

Parece lógico pensar que la antigua Carthago Nova, capital de la nueva provincia Carthaginensis a partir de la reforma de Diocleciano, debió de contar con un recinto amurallado durante el Bajo Imperio. La constatación de un recinto tardotrepublicano o augusteo, realizado mediante un doble paramento de sillería de arenisca almohadillada (Ramallo, 1989, 82-4 y 155-7), y los hallazgos en las calles de la Soledad y Orcel de lienzos y torreones pertenecientes a una muralla de época bizantina (Martínez Andreu, 1985; Laiz, Pérez y Ruiz, 1987; Ramallo, 1989, 155-7), demuestran una continuidad en la fortificación urbana de Cartagena durante todo el periodo tardoantiguo en la que una ausencia de un recinto bajoimperial sería diffcil de explicar. Sin embargo, hasta el momento no ha aparecido resto alguno de fortificación que pueda datarse en esta época. Ramallo ha planteado recientemente la posibilidad de que exista una fase anterior en las murallas bizantinas, relacionada con el proceso de amurallamiento general que se produce a finales del siglo III $\mathrm{d}$. C. en todo el Imperio (Ramallo, 1989, 156-7). Sin embargo, los datos disponibles sobre la estructura y la técnica constructiva de esta muralla (Martínez Andreu, 1985, 137-40; Laiz, Pérez y Ruiz, 1987), además del hallazgo de un fragmento de cerámica de los siglos VI-VII en la zanja de cimentación de la misma (Martínez Andreu, 1985, 130-1), no se corresponden en absoluto con las caracteristicas de una muralla de los siglos III-IV d. C.

\section{Begastri (Cehegín, Murcia)}

Las excavaciones realizadas a comienzos de los años ochenta en el yacimiento tardoantiguo de Begastri, pusieron de manifiesto la existencia de un doble recinto fortificado, el primero de los cuales se ha datado en época bajoimperial (Garcia Aguinaga y Vallarta Martinez, 1984, 53). Este presenta planta oval, con muros de 5 metros constituidos por dos paramentos de sillería y un relleno interno de piedras trabadas con mortero. En un ángulo se descubrió una puerta, protegida por uno de los lienzos que la flanquean, que avanza fuera de la línea de la muralla a la manera de una torre defensiva (Garcia Aguinaga y Vallarta Martínez, 1984, 53-5). En época bizantina el recinto inicial se amplia (Garcia Aguinaga y Vallarta Martínez, 1984, 53).

Desconocemos las razones de índole estratigráfica que han llevado a estos autores a datar este recinto fortificado, por lo que no podemos pronunciarnos sobre el particular.

\section{Ilici (La Alcudia, Elche)}

Las únicas referencias a la existencia de una muralla en la antigua llici se encuentran en los trabajos de Ramos Folqués, que recoge diversas noticias de historiadores y eruditos antiguos que describian los restos del perímetro amutallado en torno a la elevación ocupada por la ciu- 
dad romana (Ramos Folques, 1953, 325). En este mismo trabajo menciona el descubrimiento en 1880 por parte del Marqués de Lendínez, de un fragmento de muralla en el lado noroeste del yacimiento (Ramos Folques, 1957, 327). En 1975, Ramos Fernández menciona la existencia de un lienzo de muralla, posiblemente ibérico, con signos de reconstrucción posterior (Ramos Fernández, 1975, 63-5).

Ni Taracena (Taracena, 1949), ni Balil (Balil, 1960), incluyen Ilici entre las ciudades fortificadas bajoimperiales, pero, recientemente, Blázquez apunta esta posibilidad (Blázquez, 1990, 286).

\section{Castulo (Linares, Jaen)}

En 1971 se identificaron en el sector septentrional del yacimiento de Castulo, los restos de una muralla datada en el siglo III (Blázquez y Molina, 1979, 268-72). Dicha construcción estaba edificada con sillares de arenisca dispuestos en hiladas más o menos regulares y, a veces, ornamentados con un rústico almohadillado. Torreones cuadrados reforzaban la estructura a distancias casi regulares. En realidad, el único criterio cronológico empleado para fechar esta muralla ha sido, además de su técnica edilicia, el hallazgo de una inscripción donde se habla de reformas en la misma, que Blázquez, siguiendo a otros autotes, considera del siglo III. La muralla habría sido rehecha sobre la anterior, indfgena, tras una hipotética destrucción de la ciudad durante el siglo III (Blázquez y Molina, 1979, 268). En un trabajo posterior realizado con Garća-Gelabert, Blázquez se reafirma en su opinión inicial (Blázquez y García-Gelabert, 1986, 49-50). Arce mantiene que la reconstrucción del recinto defensivo tiene lugar en el siglo IV (Arce, 1982, 97-8).

En realidad, los investigadores no han aportado hasta el momento ningún argumento estrictamente arqueológico que fundamente una hipótesis bien constrastada sobte el hipotético carácter bajoimperial del recinto de Castulo. Igualmente confusa resulta su relación con la muralla indigena.

\section{Toletum (Toledo)}

Tan sólo Taracena incluye Toletum entre las ciudades dotadas de murallas en época bajoimperial (Taracena, 1949, 438-9). Este autor se fundamenta en las nunca publicadas investigaciones de D. Pedro Román Martínez, que observó en la planta de Toledo los restos de un recinto rectangular sin torreones, de $360 \times 150$ metros -unas 5 has.-, con muros de 2,60 metros de anchura realizados en sillerfa con hiladas en retirada en su parte baja y relleno interno de hormigón. La fortificación tardorromana de la antigua Toletum se encuentra en el momento actual entre las de más dudosa existencia.

\section{Abela (Avila)}

El origen romano de las murallas medievales de Avila, ha sido defendido recientemente por $\mathrm{E}$. Rodríguez Almeida (Rodríguez Almeida, 1962, 781- 2; 1981, 27-9). Este autor cree encontrar restos de sillería granítica romana en la parte inferior de los lienzos medievales, que seguirfan exactamente el trazado del recinto romano. Bajo la puerta de San Vicente, se encontraría asimismo una puerta romana flanqueada por cubos cuadrados, enmascarados por los torreones semicirculares de época medieval (Rodríguez Alameida, 1981, 27-9). Aunque este autor no da ninguna cronología al supuesto recinto romano, la existencia de una baślica paleocristiana extramuros parece indicar al menos la vigencia de éste en época tardía (Rodríguez Alameida, 1962). 
La hipótesis de Almeida presenta numerosos problemas de autenticidad. No compartimos con este autor su opinión de que los materiales y las técnicas constructivas romanas y medievales seran los mismos (Rodríguez Alameida, 1981, 28). Por otta parte, prescinde de cualquier comprobación estratigráfica. En el presente estado de cosas, no podemos dar por válido el origen romano de las fortificaciones abulenses (1).

\section{Tiermes (Montejo de Tiermes, Soria)}

Entre todas las excavaciones recientes de murallas bajoimperiales hispanas, tal vez es el yacimiento de Tiermes, el que ofrece el panorama bibliográfico más completo, que permite realizar un seguimiento exhaustivo del desarrollo de las labores arqueológicas. El conocimiento de las murallas de Tiermes es fruto de una labor arqueológica ininterrumpida durante casi diez afios, llevada a cabo por Argente Oliver y su equipo, que ha generado notables resultados (Argente Oliver, 1980; Fernández Martínez, 1980; Fernández Martínez, 1981; González Uceda, 1981 a; González Uceda, 1981 b; González Uceda, 1982; González Uceda, 1983; Fernández Martínez y González Uceda, 1984; Domenech Esteban y Alonso Lubias, 1984). Anteriores a los trabajos realizados por este conjunto de investigadores, debemos mencionar algunas citas muy escuetas (Rabal, 1888; Figueroa y Torres, 1910) y los resultados de las exploraciones y sondeos de Taracena, quien llego a datar la muralla en el siglo I d. C. (Taracena, 1941, 109).

Hasta la fecha se conoce una parte muy pequeña del recinto fortificado termestino. La ciudad ocupaba un cerro alargado - 782 X 354 metros-, con notables pendientes por sus lados occidenral y meridional, cerca de los que discurre el río Manzanares. Al parecer, la muralla no se extendía en torno a todo el perímetro urbano, sino tan sólo teforzaba los puntos por donde podía accederse más facilmente a éste, es decir, los lados norte, este y sudeste, en los que se adaptaba a la topograffa del terreno sin seguir un trazado regular (González Uceda, 1983, 356; Fernández Martínez y González Uceda, 1984, 211). La estructura defensiva delimitaba una superficie de 21 has. En 1978 se descubrió un primer torreón semicircular al noreste del recinto (Argente Oliver, 1980, 238), al que se han ido anadiendo en sucesivas campañas ottos tres cubos y varios lienzos de muraHa entre ellos, que se extienden formando un arco defensivo por las laderas noroeste, norte y noreste (Fernández Martínez, 1980, 276-7; González Uceda, 1981 a; González Uceda, 1981 b; Fernández Martínez, 1981; González Uceda, 1982; González Uceda, 1983; Domenech Esteban y Alonso Lubias, 1984, 290). Los cubos son de dimensiones irregulares, pero en general rondan los 5, 5 metros de diámetro (Argente, 1980, 238; Domenech Esteban y Alonso Lubias, 1984, 290), si bien el llamado cubo número 2 alcanza los 7 merros (González Uceda, 1981 a, 14). Tampoco las distancias a las que se disponen las torres en los lienzos guardan regularidad, alcanzando en algún caso -cubos 3 y 4 -la distancia de 26 metros (Domenech Esteban y Alonso Lubias, 1984, 290). Hasta el momento no han aparecido huellas de puertas en el recinto amurallado, a pesar de que se buscaron en el lugar que la topografía hacía más idóneo para su existencia, al norte de la ciudad (González Uceda, 1981 b, 293).

(1) Desputés de las excavaciones asqueológions realizadas por P. Barraca en el ángulo tlorceste de la muradla de Avila duranre el año 1985, en las o̧ue no enconuró hue!la alguna de construcción romara, no podennos sino cortoborar nuestra afimación, sin perjuicio de que pueda ser modificada por fururos sondeos en otros puntos del recinto. Darnos desde aquá las gracias a esta investigadora por la noticia. 
Si desde el punto de vista urbanístico, nuestro conocimiento es aún muy parcial, no podemos decir lo mismo respecto a otros aspectos. La técnica edilicia de la muralla ha sido minuciosamente descrita y comprobada en todos los puntos del recinto. Los diferentes sectores explorados manifiestan una gran uniformidad constructiva. Las descripciones más completas de la misma se encuentran tal vez en el trabajo publicado en 1981 por Fernández Martínez y en el firmado en 1984 por este mismo autor en compańfa de González Uceda (Fernández Martinez, 1981, 3189; Fernández Martínez y González Uceda, 1984, 205-9). La muralla consta de dos paramentos de sillares bien escuadrados de arenisca rojiza, dispuestos en forma de opus quadratum a soga y tizón, sobre todo en las hiladas inferiores. Las dimensiones de los bloques de piedra son muy variables, especialmente en el paramento interno de la estructura, lo que parece signo evidente de su reutilización. La unión entre los sillares se realiza en seco, y tan sólo en algunos casos aparecen huellas de grapas metálicas "en cola de milano" (Argente Oliver, 1980, 238; Fernández Martínez, 1981, 318). Se ha detectado un almohadillado muy irregular de los sillares (Fernández Martínez y González Uceda, 1984, 201). El relleno entre ambos paramentos es de hormigón muy duro, compactado con piedras calizas de pequeño tamaño y depositado en capas horizontales coincidentes con las hiladas de sillares (Fernández Martínez y González Uceda, 1984, 205). El mismo relleno se documenta en el interior de las torres (Argente Oliver, 1980, 239-40). El espesor de todo el conjunto es de unos 3, 90 metros (Fernández Martínez, 1981, 318, entre otros), alcanzando los 4 metros en algunos sectores (Domenech Esteban y Alonso Lubias, 1984, 287). A partir de la forma de unión entre torres y lienzos, Argente formula la hipótesis de que primero se edificaron aquellas, para después unirlas mediante cortinas de muro (Argente Oliver, 1980, 241). En ningún punto se ha constatado la existencia de cimnientos, a excepción del lienzo entre los cubos 1 y 2 , donde se documenta una banquera de fundación formada por una hilera de sillares en ligero resalte (González Uceda, 1983, 355).

Los paramentos han llegado hasta nosotros con tan sólo dos o tres hiladas de sillares, aunque en algunos puntos la altura conservada alcanza los 2, 40 metros (Fernández Martínez y González Uceda, 1984, 205). En el lienzo excavado al este del recinto amurallado, se detectó un retranqueo de la tercera hilada de sillares en el paramento interior (Fernández Martínez, 1980, 277), interpretado como una corrección de la curvatura que la topografia del terreno obligó a realizar en las hiladas inferiores (Fernández Martínez y González Uceda, 1984, 209). El escaso alzado de los restos conservados nos priva de una información preciosa sobre las partes altas de la muralla. Sin embargo, a partir del defectuoso acabado superior de la tercera hilada de sillares, incapaz para Fernández Martínez de sustentar hiladas superiores, este investigador plantea la hipótesis de que la fortificación termestina se completara en mampostería o ladrillo, e incluso que nunca llegara a concluirse (Fernández Martínez, 1981, 318).

Las excavaciones arqueológicas realizadas entre los años 1978 y 1984 han permitido revisar por completo la cronología de las defensas de Tiermes, establecida erróneamente por Taracena en el siglo I d. C. (Taracena, 1941, 241). El hallazgo de una moneda de Gordiano Pio, datada entre el 238 y el 244, en el nivel correspondiente a la edificación de la muralla del lienzo sureste, proporcionó la fecha post quem más ajustada hasta el momento para la fortificación termestina (Fernández Martínez, 1980, 278-9). Un análisis posterior más detenido, ha tevelado la secuencia evolutiva completa de este sector de muralla, que se superpone a varias viviendas rupestres de la segunda mitad del siglo I d. C., destruidas por un incendio un siglo más tarde y abandonadas hasta la construcción de la obra defensiva en la segunda mitad del siglo III (Fernández Martínez, 1981, 319-21). El motivo de su erección habría que ponerlo en relación 
con la supuesta segunda oleada germánica que, a decir de algunos autores, habria devastado la meseta norte hacia el $276 \mathrm{~d}$. C. No parece posible que, tal y como se había apuntado en algún momento (González Uceda, 1981 b, 294), la muralla actualmente visible sea fruto de una reconstrucción sobre una obra anterior. La interpretación estratigráfica descarta la posibilidad de una muralla del siglo II relacionada con el incendio de las estructuras preexistentes (Fernández Martínez, 1981, 320-1).

A pesar de algunas carencias significativas, como es la inexistencia de un trabajo monográfico sobre el recinto anurallado de Tiermes, el volumen de bibliografía dedicada al mismo lo convierte en uno de los mejor constatados arqueológicamente de la Península, aunque la destrucción estratigráfica haya impedido hasta el momento establecer límites cronológicos más precisos para su edificación.

\section{Uxama (Osma)}

La primera descripción de las murallas de Uxama se la debemos a Taracena (Taracena, 1949, 438), que habla de un recinto de unas 28 has., circundado por muros de hormigón revestidos con sillarejo, de unos tres metros de espesor, reforzados por tortes prismáticas de 6 metros de longitud dispuestas cada 80 metros. Este autor incluye Uxama entre los recintos bajoimperiales, seguido años más tarde, aunque con reservas, por Balil (Balil, 1960, 195-6). Ya por estas mismas fechas, García Guinea señalaba que quedaban escasos restos visibles de los lienzos y torres descritos por Taracena (Garcia Guinea, 1959, 125).

En 1970, García Metino retoma la investigación sobre la antigua Uxama, describiendo lo que queda de sus murallas (García Merino, 1970, 402-3). Esta autora circunscribe los restos conservados al sector meridional y es de la opinión de que el perímetro defensivo sólo abarco la parte más elevada del yacimiento. Aún resultaban visibles 6 torreones cuadrados, de 6, 68 metros de lado, y tres puertas, una de ellas protegida con cubos, otra dispuesta en diagonal y la tercera tallada en la roca. Los lienzos visibles parecen atestiguar la presencia de dos recintos defensivos paralelos, realizados con diferente técnica constructiva, y separados por un espacio de 1, 60 metros. El lienzo interno, conservado hasta 1 metro de altura y de grosor imprecisable, corresponde al muro de sillarejo descrito por Taracena. Los torreones pertenecerlan a este recinto, datado por García Merino en la segunda mitad del siglo III, y que podría ponerse en relación con las razzias germánicas en el Valle del Duero (García Merino, 1970, 407-8; $197 \mathrm{~L}$, 116-7). El recinto externo, construido con grandes piedras irregulares calzadas con otras más pequeñas, y de 1 metro de espesor, se trataría de una muralla celtibérica, que debió perdurar durante todo el periodo altoimperial. La autora no se muestra partidaria que ambos muros pertenezcan a un único momento constructivo, debido al empleo de diferente aparejo en cada una de sus caras y al problema de la desaparición del relleno (García Merino, 1970, 407).

La principal cuestión planteada por el supuesto recinto bajoimperial de Uxarna es la carencia de datos estratigráficos que avalen esta datación y clarifiquen el espinoso problema del doble recinto celtibérico-tardorromano.

\section{Clunia (Coruña del Conde, Burgos)}

Aún más problemática es la existencia de un tecinto amurallado en la Colonia Clunia Sulpicia, y su datación como bajoimperial. Los investigadores que han querido ver en Clunia un perímetro defensivo se basan principalmente en la descripción de Loperraez, quien vió restos de lienzos y 
correones en diversos puntos de la mesetilla ocupada por la ciudad romana (Loperraez, 1788, 321). En 1946, Taracena ya no encontraba a la vista nada de lo descrito por Loperraez (Taracena, 1946, 35). Recientemente Palol se ha mostrado escéptico sobre la posibilidad de llegar a documentar estas murallas (Palol, 1991, 23).

Ningún estudioso ha calificado estas hipotéticas murallas como tardorromanas.

\section{PROVINCIA BAETICA}

\section{Ilipa Magna (Alcalá del Río)}

En la antigua Ilipa Magna se conserva un lienzo de muralla de 1, 20 metros de espesor, con núcleo de hormigón revestido de sillares colocados a soga y tizón y torres de refuerzo cuadradas separadas por distancias de 25 metros. Thouvenot (Thouvenot, 1940,390) y Taracena (Taracena, 1949, 431-2) ya describieron en su momento esta estructura. La presencia en el interior de la misma de muretes transversales, interpretados como soportes de arcos de refuerzo sobre los que presumiblemente apoyarian las bóvedas de sosten del camino de ronda, llevó a Thouvenot a relacionarlos con las murallas aurelianas de Roma -donde aparece esta misma estructura- , considerándo estas úlimas como fecha post quem para la elevación de las muralla de Ilipa Magna (Thouvenot, $1940,390)$. Taracena, por el contrario, considera su técnica constructiva más propia del siglo II (Taracena, 1949, 433). Recientemente A. Jiménez reinterpreta los supuestos soportes de bóvedas como estribos destinados a trabar la muralla con el terreno, descartando cualquier datación a partir de las murallas aurelianas de Roma (Jiménez, 1977, 231-2). Se aleja de esta manera la posibilidad de una datación bajoimperial para el recinto ilipense.

\section{Munigua (Mulva, Sevilla)}

Thouvenot señaló la existencia en la antigua Munigua de dos recintos fortificados: el que rodeaba la ciudad, de sillares de reducido tamaño y núcleo de hormigón, reforzado con torres cuadrangulares, y una fortaleza o ciudadela en la parte alta del yacimiento, con muros de 1,56 metros de espesor realizados en mampostería con hiladas de ladrillo (Thouvenot, 1940, 387-90). Taracena considera que este último detalle constructivo demuestra que, al menos parte de la ciudadela, se edificó a finales del siglo III (Taracena, 1949, 438). En 1967, Balil, haciéndose eco de las últimas investigaciones, descarta el carácter defensivo de la supuesta fortaleza (Balil, 1967, 252, nota 24). Recientemente Grünhagen ha despejado las dudas sobre la muralla exterior, al establecer su momento de construcción en un momento posterior al $170 \mathrm{~d}$. C., tal vez relacionado con la invasión de los mauri (Grïnhagen, 1982, 323-4). No podemos por lo tanto aceptar una cronología bajoimperial para este recinto.

\section{Belo (Bolonia, Cádiz)}

Tan controvertido como el de Munigua es el carácter bajoimperial de las murallas de Belo, apuntado por Thouvenot a partir de algunas características constructivas del mismo que podrian retrasar su construcción hasta época de Galieno (Thouvenot, 1940, 392). Sin embargo, ningún autor posterior se hace eco de esta propuesta, considerándose fuera de dudas la datación 
altoimperial de este recinto (García y Bellido y Nony, 1969, 470; Mayet, 1971, 408; Jacob, $1987,146)$.

\section{Italica (Santiponce, Sevilla)}

La mayoría de los investigadores que se han ocupado de este tema considera que la colonia romana de Italica dispuso de un primer recinto fortificado de época fundacional o algo posterior, mencionado por Cesar a mediados del siglo I a. J. C. (Bellum Civile II, 20, 6). La urbanización de la Nova Urbs en época de Adriano llevó aparejada la construcción de un nuevo perímetro defensivo que, probablemente, englobaría la vieja fortificación tepublicana y abarcaba unas 30 has. (García y Bellido, 1985 (1ª ed. 1960), 86 y 125); Jiménez, 1977, 229-30). El primer plano de este recinto, levantado por Demetrio de los Ríos en 1862, fue publicado en 1886 (Zevallos, 1886, lam. III). La muralla era de hormigón revestido con sillares de reducido tamaño, reforzada con torres cuadradas y se levantaba sobre un basamenco. El ancho es de unos 1,5 metros. En algunas partes se empleó como técnica constructiva el ladrillo. En el lado norte se encontraba una puerta protegida con dos torres (García y Bellido, 1985, 125). Siguiendo a García y Bellido, algunos autores han relacionado el perfmetro amurallado italicense, más que con la creación de la ciudad adrianea, con la invasión de los mauri, que tuvo lugar hacia el 170 d. C. (García y Bellido, 1955; Taracena, 1949, 431; Santos Yanguas, 1980, 62) (2). En los últimos af́os otros investigadores se han ocupado de este recinto (Luzón Nogue, 1982, 86; Pellicer, 1982, 208-11).

A juzgar por el panorama bibliográfico, nada hacía suponer la existencia de un recinto tardfo. Sin embargo, como consecuencia de una serie prospecciones electromagnéticas llevadas a cabo en los últimos años, se ha podido documentar una posible muralla tardía con torres redondas en las esquinas y otras semicirculares y cuadradas en diversos puntos de su recorrido. La muralla, a la que se le supuesto una fecha de finales del III o principios del IV, posiblemente coincidiría con la altoimperial en el secror de la Vetus urbs, mientras que supondría una reducción considerable del perímetro de la Nova urbs, cuya población se trasladaría hacia la mitad meridional. Precisamente este sector meridional de la ciudad adrianea, encerrado por las murallas tardías, es el que ofrece mayor concentración de materiales de este periodo, razón última de la hipótesis propuesta. Esperamos que futuras excavaciones confirmen esta novedosa aportación (3).

(2) Sobre el tema de las invasiones de mauzi en la Betica pueden consultarse entre orros los mabajos de $\mathrm{R}$. Thouvenot (Thouvenot, 1939), A. Garcfa y Bellido (García y Bellido, 1955), A. Balil (Babil, 1967), E. Goalbes (Gozalbes, 1979), además del ya mencionado N. Sanzos (Santos Yangilas, 1980), rambién Gaggero (Gaggero, 1989).

(3) Damos desde açul las gracias a J. M. Rodríguez Hidalgo por su amabilidad al ofrecernos estos datos inéditos en el cranscurso de una conferencia pronunciada en la UAM. 


\section{BIBLIOGRAFIA}

Aimagro Basch, M., 1962: Ampurias, Exc. Arq. Esp. 9, Madrid.

... 1964: Excavaciones en la Palaiápolis de Ampurias, Exc. Arq. Esp. 27, Madidid.

AQuILUE, J. Y VV.AA., 1984: El Forum Romá d'Empuries, Barcelona.

ARCE, J., 1982: El uiltimo siglo de la España romana: 284-409, Madrid.

ARGENIE OuIVR, J. L., 1980: "Campaña de 1978: la muralla romana", Tiermes I, Exc. Arq. Esp.111, Madrid, 237-50.

ARIAS Vitas, F., 1972: La muralla de Lugo, Studia Arqueologica 14, Santiago.

ARRIBAS, A, 1983: "Pollentia: problemas de topografia y conservación de la ciudad", Symposium de Arqueologia: Pollentia y La Romanización de las Baleares, Mallorca, 35-46.

ARribas, A, TARradeli, M. Y WoOdS, D. E., 1973: Pollentia I. Excavaciones en Sa Portella, Alcudia (Mallorca), Exc. Atq. Esp. 75, Madrid.

1..1978: Pollentia II, Exc. Arq. Esp. 98, Madrid.

ARribas, A. y TARRADELL, M., 1987: "El Foro de Pollentia. Noticia de las primeras investigaciones", Los Foros Romanos de las Provincias Occidentales, Madrid, 1987, 121-36.

Aveila, L. C., 1984-85: "Las monedas de la Torre de Minerva", Butlleti Arqueoldgic época V, 6-7, 55-62.

Balll, A., 1957: "La cronologia de las fortificaciones de Barcino en el Bajo Imperio", IV C.N.A. (Burgos, 1955), Zaragoza, 227-30.

... 1958: "Sobre la fortificación del Bajo Imperio en Hispania: las puertas de la muralla de Barcino", Actas I Congreso Español de Estudios Clásicos (Madrid, 1956), Madrid, 279-80.

... 1960: "La defensa de Espania en el Bajo Imperio", Zephyrus XI, 179-97.

... 1961: Las murallas romanas de Barcelona, Anejos A, Esp. A. II, Madrid.

... 1962: "Mosaicos ornamentales romanos de Barcelona", A. Esp. A. 105-6, 36-69.

... 1963: "Las fortificaciones del Bajo Imperio en las provincias romanas de Espana", Celticum XI, 293-6.

... 1965: "Urbanismo romano en la España céltica", Celticum XII, 275-88.

... 1964: Colonia Iulia Augusta Paterna Faventia Barcino, Madrid.

... 1967: "De Marco Aurelio a Constantino. Una introducción a la España del Bajo Imperio", Hispania $106,245-341$.

.. 1970: "La defensa de Hispania en el Bajo Imperio. Amenaza exterior e inquietud interna", Legio VII Gemina, León, 601-20.

BASSEGODA NONELL, J., 1975): "En la vieja Plaza Nueva, la torre del Obispo", Información Arqueológica, 101-5.

BEDON, R, CFiEvaijer, R, Y PiNON, P., 1988): Architecture et urbanisme en Gaule romane, Paris.

Beltran Lloris, M., 1967: "Las ánforas del Museo Arqueológico de Zaragoza", X C.N.A. (Mahón, 1967), Zaragoza, 408 y ss.

... 1970: Las anforas romanas en España, Zaragoza.

... 1976: "Un corte estratigráfico en la Zaragoza romana", Symposium Ciudades Augusteas II, Zaragoza, 8798.

Beltran Lloris, M. y VV.AA., 1980; Caesaraugusta I (campaña 1975-1976), Exc. Arq. Esp. 108, Madrid. ... 1985: "La arqueologia urbana en Zaragoza", Arqueologia ciudades modernas superpuestas a las antiguas (Zaragoza, 1983), Zaragoza, 55-116.

Blazquez, J. M. y Molina, F., 1979: "La muralla de Cástulo", Castulo II, Exc. Arq. Esp. 105, Madrid, 269-84.

Blazquez, J. M y GarCla-Gelabert, Ma. P., 1987: "El iberismo de la ciudad de Cástulo", Los asentamientos ibtricos ante la romanizacion (Madrid, 1986), Madrid, 49-50.

BlAZQUEZ, J. M, 1980: "Luftaufnahmen ummauerter Städte dert Spätantike in Spanien", Der römische Limes in Osterreich, 36, 1 (Akten des 14 Internationalen Limeskongresses 1986 in Carnuntum), Wien, 281-94.

BOSCH GIMPERA, P., 1919; Prehistoria catalana, Barcelona. 
Botet i Siso, J., 1909: "Provincia de Gerona", F. Carreras Candi (dir.), Geografia General de Catalunya, Barcelona.

BRAVO, G., 1989: Poder político y desarrollo social en la antigua Roma, Madrid.

CozzA, L., 1986: "Mura Aureliana 1", B.C.A.C.R. XCI, 1, Roma.

... "Osservazioni sulle mura aureliana a Roma", Analecta Romana I. Danici, Roma.

CRICKMORE, J., 1984: Romano British Defences, B.A.R. 126, Oxford.

DOMENECH ESTEBAN, M. y ALONSO LuBIAS, A., 1984: "Excavaciones arqueológicas en Tiermes. (Informe preliminar de la décima campaña 1984). IV. Muralla romana", Celtiberia 68, 286-94.

DURAN y SANPERE, A., 1934: L'arguitectura romana a Catalunya, Barcelona.

... 1943: "Vestigios de la Barcelona romana en la Plaza del Rey", Ampurias 5, 53-77.

... 1945: Noticias de excavaciones. Bajada de la Canonja y calle de los Condes, Divulgación Histórica, I.

... 1969: "La corre poligonal ( $\mathrm{n}^{\circ} \mathrm{G}$ ) de la mutalla romana", Cuad Arq. Historia Ciudad XIII, 51-67.

ELORZA, J. C., 1972: "A propósito de la muralla romana de Iruña (Alava)", Est. Arq. Alavesa 5, 183-94.

EuZENAT, M., 1989: Le limes de Tingitane. La frontizre meridionale, Paris.

FERNANDEZ DE AVILES, A., 1956: "Excavaciones en Logroño (1945): Monte Cantabria y el Redal", Rev. Berceo XL, 329-43.

FERNANDEZ MARTINEZ, V, 1980: "Informe de la 5 a campaña de excavaciones arqueologicas en Tiermes (Montejo de Tiermes, Soria), realizada en el verano de 1979. Muralla tardorromana", Celriberia 60, 276-9.

.. 1981: "La muralla romana de Tiermes. Resultados de la campafia de excavaciones de 1980. Elementos para su datación", Celtiberia 62, 317-23.

Fernandez Martinez, V. y Gonzalez UCEDA, A., 1984: "La muralla romana", Tiermes II, 128 Exc. Arq. Esp., Madrid, 197-291.

FERRIL, A., 1989: La caida del Imperio Romano. Las catsas militares, Madrid.

FiCK, A., 1930: "Die Römischen Stadtmauer von Gerona", Archäologischen Anzeiger, 266-75.

Figuera LezCANO, L. DE LA, 1934: "La muralla de Caesaraugusta", Anuario Cuerpo Facultativo Archiveros, Bibliotecarios y Arqueólogos. Homenaje a J. R. Melida II, 159-61.

FigUerOA y TORRES, A. DE, 1910: Las minas de Tiermes. Apuntes arqueologicos descriptivos, Madrid.

FiorenSA, A., 1958): Las murallas romanas de la ciudad de Barcelona, Barcelona.

GAGGERO, G., 1989: "I mauri nella storiografia del tardo ímpero", L'Africa romana 1, Sassari, 299-309.

Gaive, M. P. y Magallon, M. A., 1975: "La epigrafia romana de Caesaraugusta", Miscelanea Arqueologica dedicada a Antonio Beltrán, Zaragoza, 213-30.

GarCIA Y BelidDo, A., 1955: "Las primeras invasiones moras (época romana) en España", Arch. Inst. Est. Africanos 33, 31-9

... 1985: Andalucia Monumental. Italica ( $1^{\text {a }}$ ed. 1960), Sevilla.

Garcia y Bellido, A. y NonY, D., 1968: "Les fouilles de la Casa de Velázquez à Belo (Bolonia, Cadix) en 1968", MeL Casa Veldaquez 5, 465-78.

Garcia Aguinaga, J. L. y Vallarta Martinez, M. P., 1984: "Fortificaciones y puerta de Begastri", Antigüedad y Cristianismo I: Begastri, Murcia, 53-61.

Garcia Gunnea, M. A., 1959: "Prospecciones en la antigua Uxama", A. Esp. A. 32, 122-34.

Garcia Guinea, M. A., Gonzaifz Echegaray, J. y SAN Miguel Ruiz, J. A., 1966: Excavaciones en Monte Cilda, Olleros de Pisuerga (Palencia). Campañas de 1963-65, Exc. Asq. Esp. 61, Madrid.

Garcia Guinea, M. A., Iglesias Gi, J. Mª y Caioca, P., 1973: Excavaciones de Monte Cilda, Olleros de Pisuerga (Palencia). Campañas de 1966 a 1969, Exc. Arq. Esp. 82, Madrid.

Garcia Merino, C., 1970: "La ciudad romana de Uxama", B.S.E.A.Arq. 36, 381-439.

... 1971: "La ciudad tomana de Uxama (II)" B.S.E.A.Arq. 37, 85-124.

Gil ZubillaGA, E.; Filloy, I e IRIARTE, A, 1991: "Estructuras urbanas en el yacimiento romano de Inuña

(Trespuentes, Alava), Estado de la cuestión", La Casa Urbana Hispanorromana Zaragoza, 21 8-286.

GOMEZ-PANTOjA, J., 1976: "La ciudad romana de Calahorra", Symp. Ciudades Augrusteas, Zaragoza, 185-88. 
Gonzalez UCEDA, A., 1981 a: "Muralla romana de Tiermes", Arevacon 4, 14.

... 1981 b: "Excavaciones arqueológicas en el yacimiento de Tiermes. Informes preliminares de la $7^{\text {a }}$ campaña. 1981. IV: Muralla romana", Celtiberia 62, 293-4.

...1982: "Excavaciones arqueológicas en el yacimiento de Tiermes. Informes preliminares de la octava campaña (1982). IV: Muralla romana", Celtiberia 64, 346-8.

... 1983: "Excavaciones arqueológicas en Tiermes. Informes preliminares de la novena campaña (1983). IV: muralla romana", Celtiberia 66, 355-7.

GozAi.BES, E., 1979: "Incursiones de moros contra la Betica en el mundo antiguo", Jabega 26, 50-3.

Granados, J. O., 1976 a: "Notas para el estudio topográfico de la Colonia Barcino en el siglo I: la primera muralla de la ciudad", Sympositum Ciudades Augusteas II, Zaragoza, 215-24.

... 1976 b: "Estudios de arqueologfa romana barcelonesa: la puerta Decumana o del noroeste", Pyrenae 12, 157-71.

.. 1977-78: "Excavación de la torre de flanqueo sudoeste de la puerta Decumana de la Colonia Barcino", Pyrenae 13-14, 253-73.

... 1984: "La primera fortificación de la Colonia Barcino", B.A.R. Int. Series 193 (1): Papers in Iberian Archaeology, 267-319.

GRUTHAGEN, W., 1982: "Cronologia de la muralla de Munigua", Homenaje Saenz de Buruaga, Madrid, 315-28.

Hallier, G., 1986: "La fortification des villes de Tingitane au second siècle", F.Ber.Bad. Wiirt 20, Stutrgart.

HAuschild, 'T., 1979: "Die römische Stadtmauer von Tarragona. Ausgrabungen in der Torre Minerva und in Baluarte de Sta. Bárbara. Kampagnen 1976 bis 1978" M. M. 20, 204-37.

... 1984-5: "Excavaciones en la muralla romana de Tarragona", Butlleti Arqueologic, época V, 6-7, 11-38.

HeRNANDEZ VERA, J. A., 1978: "Las ruinas de Inestrillas", Caesaratugusta 45-6, 63-66.

.. 1982; Las ruinas de Inestrillas. Estudio arqueologica. Aguilar del Rio Alhama, La Rioja, Logrono.

IŇIGUEZ, F., 1959: "La muralla romana de Zaragoza", C.A.N. V(Zaragoza, 1957), Zaragoza, 253-68.

JACOB, P., 1986: "Belo Claudia e son contexte", Los Asentamientos ibericos ante la Romanización, (Madrid, 1986), Madrid, 141-54.

JaRREGA DOMingueZ, R, 1991: "Consideraciones sobre la cronologia de las murallas tardorromanas de Barcelona: una fortificación del siglo V", A. Esp. A. 64, 326-35.

Jimenez, A. 1977: "Arquitectura romana de la Bética", Symp. Arq. Romana, (Segovia, 1977), Barcelona, 223-38.

JOHNSON, S., 1983: Lase Roman Fortifications, London.

Jusue, C., 1985: "Recinto amurallado de la ciudad de Olite", Trabajos de Arqueologia Navarra IV, Pamplona, 227-35.

LACARRA, J. M., 1945: Estudios de la Edad Media de la Corana de Aragón I, Zaragoza.

LANDER, J., 1984: Roman Stone Fortifications. Variation and Change from the First Century A.D. to the Fourth, B.A.R. 206, Oxford.

LARA PeINado, F., 1970: "La "Tlerda" romana", XI CA.N. (Mérida 1968), Zaragoza, 627-62.

... 1973: Lérida romana, Lérida.

LaIz, Ma. D., Perez, L.M. y Rulz, E., 1987: "Nuevos hallazgos bizantinos en Cartagena”, A. Esp. A. 60, 281-5.

LENOIR, E., 1983-84: "Tradition hellenisrique et rechniques romaines dans las enceintes urbaines du Maroc", La fortification dans l'bistoire du monde grec, Paris.

LOPERRAEZ, J., 1788: Descripcibn historica del Obispado de Osma, II, Madrid.

LUZON NoGUE, J. M", 1982: "Consideraciones sobre la urbanística de la ciudad nueva de Iralica", Actas I Jornadas Exc. Arq. en Italica, Italica (Santiponce, Sevilla), Exc. Arq. Esp. 121, (Sevilla, 1980), Madrid, 75-96.

MAioneY, J. y Hobley, B., 1983: Roman Utban Defences in the West, London.

MARTINEZ ANDREU, M., 1985: "La muralla bizantina de Carthago Nova", Antigiziedad y Cristianismo II, 129-52.

MAYET, F., 1970: "La cínquiènne campagne de fouilles a Belo (Bolonia, provincia de Cadix) en 1970", Mel. Casa Vel. 7, 405-18. 
MC NICOLL, A., 1986: "Development in Techniques of Siegecraft and Fortifications in the Greek World", La fortification dans l'bistoire du monde grec, Paris.

Mezquiriz de Catalan, Ma A., 1958: Pompaelo l. Campaña de 1956, Pamplona.

... 1976: "Algunas aportaciones al urbanismo de Pompaelo", Symp. Ciudades Auqusteas II, Zaragoza, 189-93.

... 1978: Pompalo II, Pamplona.

MORLlio CERDAN, A., 1991: "Fortificaciones campamentales de época romana en España", A. Esp. A. 64, $135-90$.

MORO, R., 1891: "Monte Cildá", B. R A. H. XVIII, 426-32.

Nieto Gallo, G., 1958: El opidum de Iruña, Viroria.

NiETO, F. J., 1981: "Acerca del progresivo despoblamiento de Ampurias", Riv. St. Lig. XIVII, 34-51.

NOLLA, J. M., 1977: La ciudad romana de Gerunda, Tesis Doctoral Inédita, Univ. Autónoma Barcelona.

... 1978 a: La ciudad romana de Gerunda, Resumen Tesis Doctoral, Univ. Autónoma Barcelona.

... 1978 b: "Excavacions arqueologiques a Girona: sondatges i troballes a la Plaça de Sant Domenec", Rev.

Girona 85, 367-73.

... 1979: "Excavacions i sondeigs a Girona: Les obres del Passeig Arqueologic", Rev. Girona 87, $101-8$.

... 1979-80: "Noves aportacions a l'estudi dels origens de Gerunda", Annals de l'Institut d'Estudis Giromins XXV-I, 107-18.

... 1980: "Excavacions arqueológiques a Girona: la Caserna d'Alemanys", Cypsela III, 179-92.

... 1987: Girona romana: De la fundació a la fi del món antic, Quaderns d'Història de Girona, Girona.

NOLLA, J. M. y NiETo PRieto, F. J., 1979: "Acerca de la cronologfa de la muralla romana tardfa de Gerunda: la terra sigillara clara de "Casa Pastors", Favention 1-2, 263-83.

Nolla, J. M. y VV.AA., 1989: "El sector oriental de les muralles de Gerunda. Noves aportacions al seu coneixement (Campanya d'excavacions de 1987 a la rorre Gironella)", Cypsela VII, 111-30.

NOLlA, J. M. y SAGrerA, J., 1990: "El "Portal" de Levante de la ciudad de Gerunda", A. Esp. A. 63, 276-82.

Ourva, M., 1965: "Recintos fortificados de tipo "ciclópeo" en rierras gerundenses", Coloquio Arquitectura Megalitica y Ciclópea Catalano-Balear, Barcelona, 89-110.

... 1976: "Excavaciones arqueológicas en la provincia de Gerona, en 1973", N. A. Hco. Prebistoria 5, 140.

OrIol Granados, J. M. y VV. AA., s/f. La porta romana del Pati d'en Llimona, Carrer del Regomir, Barcelona.

Pallares, F., 1969: "Las excavaciones de la plaza de San Miguel y la ropografia romana de Barcino", Cuad. Arq. Historia Ciudad XIII, 5-42.

... 1970: "La ropografia e gli origini di Barcellona romana", R. St. Lig. XXXVI, 63-102.

PaLOL, P. DE, 1991: "Clunia Sulpicia, ciudad romana. Su historia y su presente", Clunia 0, Burgos, 9-74.

PASCUAL, J. M"2, 1979: "Hallazgos superficiales en Monte Cantabria (Logrofio)", Cuad Investización Geografta

e Historia V, 1, Logrońo, 51-64.

PelliCer, M., 1982: "Excavaciones en Italica (1978-79). Muralla, cloacas y cisterna", Actas I Jornadas sobre

Exc. Arq. en Italica, Italica (Santiponce, Sevilla), Exc. Arq. Esp. 121 (Sevilla, 1980), Madrid, 205-24.

PEREZ I ALMOGUeRA, A, 1984: La ciutat romana d'llerda, Lleida.

PERez ArRondo, C., 1979: "Excavaciones arqueológicas en Monte Cantabria, 1977. Informe preliminar",

Cuad. Invest. Geografia e Historia V, 1, Logrono, 65-90.

Petrikovits, H. V., 1971: "Fortifications in the North-Western Roman Empire from the Third to the Fifth Centuries A.D.", Journal of Roman Studies, LXI, London.

Rabal, M., 1888: "Informes 1. Una visita a las ruinas de Termancia", B. R. A. H. XII, 455.

RAHOLA, C. La ciutat de Girona I, Barcelona, 65.

RAMALLO, S., 1989: La ciudad romana de Carthago Nova: la documentación arqueologica, Murcia.

RAMOS AGUIRRE, M., 1987: "Cuestiones sobre las fortificaciones romanas de Olite", I Congreso Gral Historia Navarra 2, Anejos Rev. Principe Viana 7, Pamplona, 577-580.

RAMOS Folques, A., 1953: "Mapa arqueológico del término municipal de Elche (Alicante)", A. Esp. A. 26, 323-54. 
RAMOS FERNANDEZ, R., 1975: La ciudad romana de llici. Estudio arqueológico, Alicante.

ReBUfATT, R., 1974: "Enceintes urbaines et inségurité en Maurétanie Tisgitane", M.EFRA, 86, Roma, 501-22. ... 1986: Les fortifications urbaines romaines", La fortification dans l'histoire du monde grec, Paris, 345-61. RicHMOND, I. A., 1931: "Five Town-walls in Hispania Citerior", J. R. S. XXI, 86-100.

RODRiguez AimeidA, E., 1962: "La primitiva memoria martirial de los Santos Vicente, Sabina y Cristeta", Atti VI Congreso Int. Arch. Cristiana, Ravenna, 781-97.

... 1981: Avila romana, Avila.

SAN MARTi, E., CASTAÑeR, P. y TREMOLEDA, J., 1988: "La secuencia histórico-topográfica de las murallas del sector septentrional de Emporiae", Madrider Mitt 29, 191-200.

SANTOS YanguAS, N., 1980: "Las invasiones de moros en la Bética del siglo II d. N. E.", Gades 5, 51-62.

SERRA-RAFOLS, J. DE C., 1927-31: "Les muralles ibériques y romanes de Girona", Anuari de l'Institut d'Estudis Catalans VIII, 69-85.

... 1941: "Excavaciones en Gerona", Mem. Mus. Arq. Prov. II, 42.

.. 1942 a: "Excavaciones en las murallas romanas de Gerona", Mem. Mus. Arq. Prov. III, 87-8.

... 1942 b: "El recinto antiguo de Gerona", A. Esp. A. XV, 114-35.

... 1967: "Els origens de les fortificacions", Els Castells Catalans I, Barcelona, 25 y 46-50.

... 1959: "Las excavaciones de la muralla romana de la calle Tapinería, de Barcelona", Zephyrus X, 129-41.

... 1964: "Notas sobre el secror nordeste de la muralla romana de Barcelona", Cuad. Arq. Historia Ciudad, V, 5-64.

... 1967: "Balanç i estat actual de l'estudi de la mutalla romana de Barcelona", Cuad Estudios Historia Cizudad $10,129-48$.

Serra Vilaro, 1., 1949: "La muralla de Tarragona", A. Esp. A., 221-36.

SOL Valies, J., 1977: "Mernoria de los trabajos realizados en la zona B de la Plaza de San Miguel y en la muralla romana de Barcelona, 1973", N. A. Hco. Arqueologia 5, 79-87.

Taracena, B., 1926: "Noticia de un despoblado junto a Cervera del río Alhama", A. Esp. A. y A., 4-5, 137-142.

... 1941: Carta arqueologica de España. Soria, Madrid.

... 1942: "Restos romanos en la Rioja", A. Esp. A., 17-47.

... 1947: "El palacio romano de Clunia", A. Esp. A. XIX, 29-69.

... 1949: "Las fortificaciones y la población de la España romana", Congreso Arq. Sureste Español TV, (Elche, 1948), Zaragoza, $421-41$

Taracena, B. y VazQuez de ParGa, C., 1947: Excavaciones en Pamplona I. 1942-1946. La romanización, Pamplona, 115-8.

TARADELI, M., 1977: "Primeres noticies de la crisi del segle III d. J. C. a Mallorca", Univensitat de Barcelona. Institut d'Arqueologia i Prehistòria. Memòria, 27-32.

... 1978: Les ciutats romanes dels Päisos Catalans. Discurs d'ingrés a la Reial Acadèmia de Bones Lletres de Barcelona, Barcelona.

Thourvenot, R., 1939: "Les incursions des maures en Betica sous Mosc-Aurele", Revue Etudes Anclennes $41,20-8$.

... 1940: Essai sur la province romaine de Bétique, Paris.

VERRIE, F. P. y VV. AA., 1973: "Actividades arqueológicas del Museo de Historia de la Ciudad en los últimos cinco años (1966-1970)", Actas XII C.N.A. (Jaén 1971), Zaragoza, 769-88.

Vielacampa Rubio, M. A., 1979: "Historiografía de Monte Cantabria (Logrofio)", Cuad. Investigación Geografia e Historia V, 1, Logrono, 41-50.

WEBSTER, G. (ed.), 1988: Fortress into City. The Consolidation of Roman Britain. First Century A.D., London.

WELSBY, D. A., 1990: "Observations on the Defences of Roman Forts in North Africa", Antiquites Africaines 26, Paris.

Zevalios, F. DE, 1886: La Italica, Sevilla, 